\title{
A high-quality monthly total cloud amount dataset for Australia
}

\author{
Branislava Jovanovic • Dean Collins • Karl Braganza • \\ Doerte Jakob • David A. Jones
}

Received: 11 May 2009 / Accepted: 5 November 2010 / Published online: 16 December 2010

(C) The Author(s) 2010. This article is published with open access at Springerlink.com

\begin{abstract}
A high-quality monthly total cloud amount dataset for 165 stations has been developed for monitoring and assessing long-term trends in cloud cover over Australia. The dataset is based on visual 9 a.m. and 3 p.m. observations of total cloud amount, with most records starting around 1957. The quality control process involved examination of historical station metadata, together with an objective statistical test comparing candidate and reference cloud series. Individual cloud series were also compared against rainfall and diurnal temperature range series from the same site, and individual cloud series from neighboring sites. Adjustments for inhomogeneities caused by relocations and changes in observers were applied, as well as adjustments for biases caused by the shift to daylight saving time in the summer months. Analysis of these data reveals that the Australian mean annual total cloud amount is characterised by high year-to-year variability and shows a weak, statistically non-significant increase over the 1957-2007 period. A more pronounced, but also non-significant, decrease from 1977 to 2007 is evident. A strong positive correlation is found between all-Australian averages of cloud amount and rainfall, while a strong negative correlation is found between mean cloud amount and diurnal temperature range. Patterns of annual and seasonal trends in cloud amount are in general agreement with rainfall changes across Australia, however the high-quality cloud network is too coarse to fully capture topographic influences. Nevertheless, the broadscale consistency between patterns of cloud and rainfall variations indicates that the new total cloud amount dataset is able to adequately describe the broadscale patterns of change over Australia. Favourable simple comparisons between surface and satellite measures of cloudiness suggest that satellites may ultimately provide the means for monitoring long-term changes in cloud over Australia. However, due to the relative shortness and homogeneity problems of the satellite record, a robust network of surface cloud observations will be required for many years to come.
\end{abstract}

B. Jovanovic $(\varangle) \cdot$ D. Collins · K. Braganza · D. Jakob · D. A. Jones

National Climate Centre, Australian Bureau of Meteorology,

GPO Box 1289, Melbourne, 3001, Australia

e-mail: b.jovanovic@bom.gov.au 


\section{Introduction}

Clouds are a visible manifestation of thermo-dynamic processes in the atmosphere. Cloud cover has a major impact in regulating the earth's weather and climate by producing precipitation, reflecting shortwave solar radiation back to space and returning outgoing longwave radiation towards the earth (Solomon et al. 2007).

By reflecting shortwave radiation and absorbing longwave radiation, clouds exert somewhat compensating effects on the Earth's radiation budget. Different cloud types affect this budget in different ways. For example, low and middle level clouds reflect solar radiation which leads to reduced daytime temperatures, while lower albedo higher level cirrus has little effect on incoming sunlight, and typically causes a surface warming through absorption of longwave radiation. A strong inverse relationship is expected between TCA and DTR because clouds act both to hinder daytime warming, and to reduce overnight cooling (Henderson-Sellers 1992).

Climatological changes in cloud amount can force long-term changes in maximum and minimum temperatures. The diurnal temperature range (DTR) is particularly sensitive to changes in cloud cover (Dai et al. 1999), and several studies have shown that changes in DTR are a significant indicator of climate change over the last 50 years (e.g. Braganza et al. 2004; Stone and Weaver 2003). At the same time, the response of cloud cover to increasing greenhouse gases represents one of the largest internal sources of uncertainty in model predictions of climate change (Bony et al. 2006). Correctly characterising historic changes in cloud cover, as well as changes in cloud types and other properties such as cloud top temperature and optical thickness, is therefore an important component of climate change monitoring (Dai et al. 2006).

Although limited by potential biases due to changes in observation practices, surface-observed cloud amount provides the longest available record of cloud cover. While satellite data provide better spatial and temporal sampling, these data are also subject to biases caused by the drift in observation time during a satellite mission (Jacobowitz et al. 2003), instrument changes between missions, and the gradual decay of satellite orbits (Trenberth 2002). Even if these problems can be overcome, and satellites ultimately become the means for long-term monitoring of cloud amount, good quality surface records will be required for ground-truthing purposes.

Many analyses of surface-observed cloud amount suggest an increase over continental regions since the middle of the last century, including USA (Groisman et al. 2004; Dai et al. 2006), parts of Canada (Milewska 2004) and the former USSR (Sun and Groisman 2000; Sun et al. 2001). In contrast, decreasing cloudiness over the same period has been reported over much of China (Kaiser 1998, 2000) and South Africa (Kruger 2007), as well as over Italy (Maugeri et al. 2001) and central Europe (Auer et al. 2007).

A comprehensive study of global trends in cloud amount was undertaken by Warren et al. (2007). The study found a small negative trend in global average cloud cover over land for the period 1971 to 1996, which was compensated by a small positive trend over the ocean, resulting in almost no trend for global average cloud cover over the period considered. The study also revealed significant variability over Australia associated with El Niño-Southern Oscillation (ENSO).

For Australia, a study by Jones and Henderson-Sellers (1992) found a rise in cloud cover of $5 \%$ between 1910 and 1989, with most of the increase occurring between 
1930 and 1980. The study was based on a dataset of monthly mean cloud cover from a network of 318 stations. However, limited quality checking was undertaken on these data and it is possible that inhomogeneities in the dataset may have affected the analysis.

As described below, there are a number of substantial inhomogeneities in total cloud amount timeseries as a result of both random and systematic variations in observing practices and locations through time. Prior to this study no homogenised cloud dataset for Australia existed which had been specifically developed for the purposes of monitoring climate variability and change. It is the purpose of this study to address this gap and briefly analyse long term changes in Australian cloudiness up to the present.

\section{Data and stations used}

In Australia, cloud amount, type and height are estimated visually by professional observers at weather stations, as well as by trained co-operative observers (for example at agricultural research stations or Post Offices), following the general rules outlined in the Field Operational Documents (BoM 2001). Total cloud amount (TCA) is defined as the fraction of the sky covered by clouds at any height, and is estimated in oktas (1/8th of the sky). A totally overcast sky is recorded as 8 (eight) and a clear sky is recorded as 0 (zero). A sky with any trace of cloud less than 1 okta is coded as 1 okta while any trace of blue in an otherwise overcast sky is coded as 7 oktas. Consequently, an upward bias exists in reports for low TCA amounts and a downward bias exists in reports of high TCA values. Observed TCA data are reported to the Bureau of Meteorology, where they are quality checked and archived electronically in the Australian Data Archive for Meteorology (ADAM).

TCA is a subjective observation, but is the simplest of all cloud measures undertaken by human observers. Estimating accurate cloud heights, thicknesses and types requires greater meteorological understanding and experience and, consequently, these measures are likely to involve more subjectivity and error than TCA. For this reason, this study has limited the rehabilitation ${ }^{1}$ of the Australian cloud record to the simple measure of TCA. The fact that TCA is a human estimate means that the precision of the observer's estimate can be relatively low. However, if the sample size is large enough, the results should be of a good quality.

Over the past century, TCA data have been recorded at more than 1,600 stations around Australia. The number of operating stations recording TCA peaked in 1969 with 896 and then decreased to 496 in 2007, as a result of the closure of manual sites often associated with the introduction of Automatic Weather Stations (AWSs). This trend towards automation will, most likely, continue into the future causing a further decline in the number of stations which take cloud observations.

\footnotetext{
${ }^{1}$ In this context, rehabilitation means detection of, and adjustment for, data inhomogeneities in order to obtain a high-quality data series suitable for examining trends.
} 
For this study, only stations that currently record TCA and have at least 35 years of mostly continuous TCA data were considered. To increase the number of available stations, records from some open stations were combined with those from closed neighboring stations to create composite records. This resulted in around 200 potential high-quality TCA stations.

It was decided that the variability and subjectivity in daily TCA records would make rehabilitation at the daily time scale difficult. Consequently, monthly TCA series for the observation times of 9 a.m. and 3 p.m. local standard time were generated for each station by averaging all available daily values for 9 a.m. and 3 p.m. respectively. If more than five 9 a.m. (3 p.m.) values were missing during a month, then the monthly mean 9 a.m. (3 p.m.) value was classified as missing. An annual TCA value was generated from the monthly values only if all monthly means were available. Generally, there was a very good agreement between variations in monthly and annual means of morning (9 a.m. local standard time) and afternoon (3 p.m. local standard time) TCA series from the same site (see Fig. 1 for example at Canberra Airport).

Only 9 a.m. and 3 p.m. TCA records were used because these two times have the longest and most complete TCA records of all observation times. In Australia, 9 a.m. local time has long been the official recording time for daily rainfall amount and 24-h maximum and minimum temperatures. A 3 p.m. observation is usually taken to provide a preliminary value of daily maximum temperature before the final value is recorded at 9 a.m. the following day. With the rationalisation of the observation network, many observation schedules have been reduced to just 9 a.m. and 3 p.m., or even just the 9 a.m. observation.

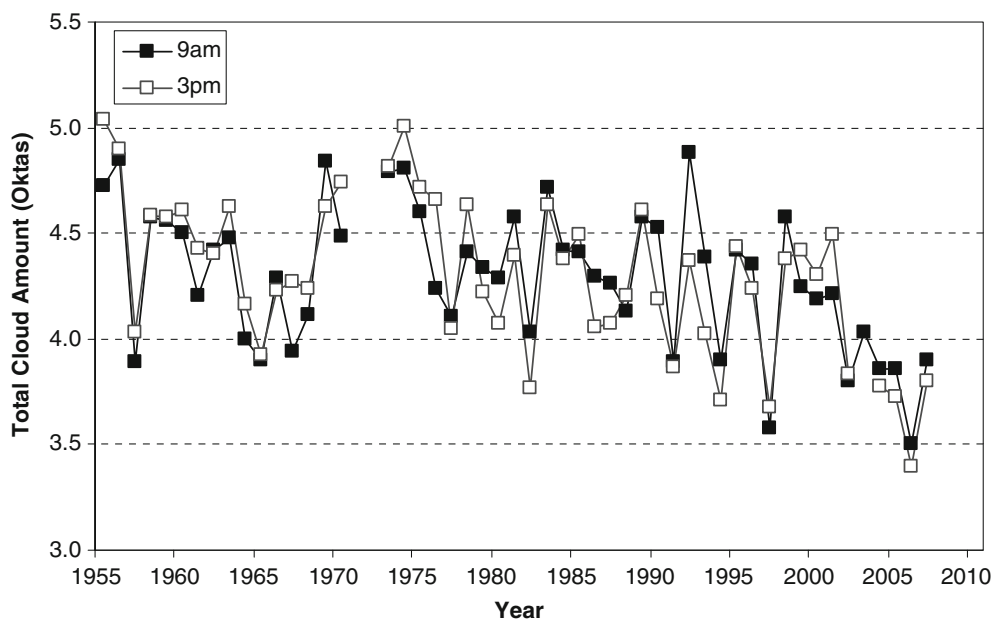

Fig. 1 Comparison of annual mean 9 a.m. and 3 p.m. TCA series for Canberra Airport (70014). Correlation coefficient $r=0.86$ 
The dataset presented here begins in 1957, due to limited digitised daily and hourly records prior to that year (Clarkson 2002). An additional reason relates to a change in observing practice that took place from 1949, when a revised International Code was brought into force (Henderson-Sellers 1992). Until 1949 observations of TCA were made in tenths of sky cover, while after 1949 they were made in eighths (oktas). By limiting data to the period after this change a potential data discontinuity can be avoided.

Before inclusion in the dataset, a series of quality assessments were applied to each potential high-quality TCA record. These included checks for data completeness, as well as checks for consistency with TCA from neighboring stations and records of physically related, but independently measured, variables from the same site, such as sunshine hours, rainfall and DTR. An example for Canberra Airport is shown in Fig. 2.

All stations were assessed for quality on a 1 to 5 scale (see Appendix), with rank 1 being very poor and 5 being very good. Only stations with a rank of 3 or higher were retained in the final dataset. Ranks were subjectively assigned, taking into account the number of changes in observers, number of site moves and the amount of missing data. After this quality assessment, a total of 165 stations were selected for the highquality TCA dataset. The majority of these stations coincide with stations in the highquality daily temperature (Trewin 2001) and relative humidity (Lucas 2006) datasets, which are used to monitor temperature and moisture trends across Australia.

The final set of 165 stations selected for the high-quality TCA dataset is given in Appendix and their spatial distribution is shown in Fig. 3. The network has reasonably good coverage over most parts of Australia, but has notable gaps in the largely uninhabited inland of Western Australia and western South Australia, and sparse coverage across the Northern Territory.

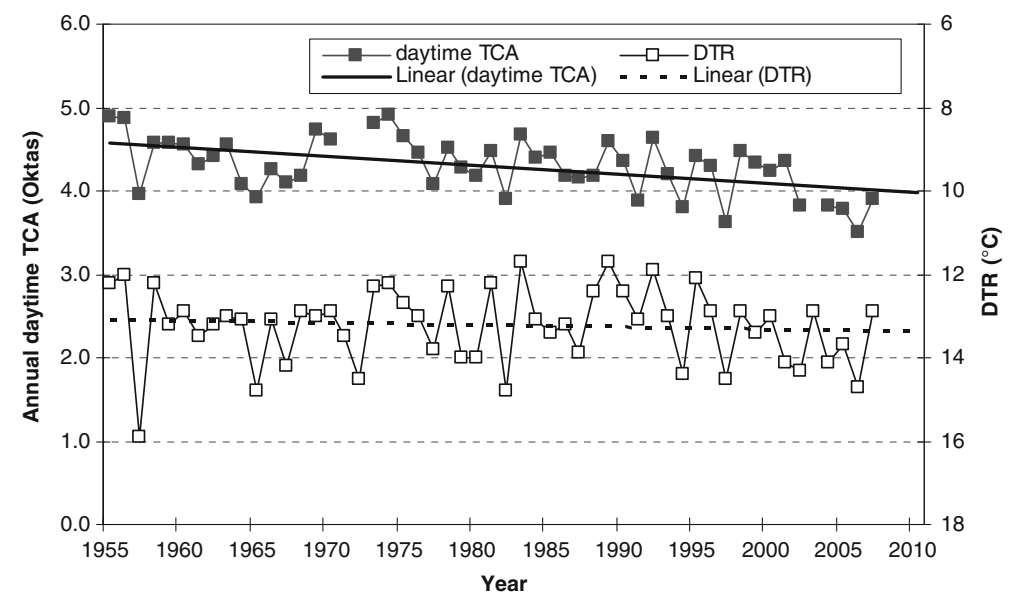

Fig. 2 Comparison of annual mean daytime TCA and DTR for Canberra Airport (70014). Correlation coefficient $r=-0.75$. Note inverted scale for DTR 


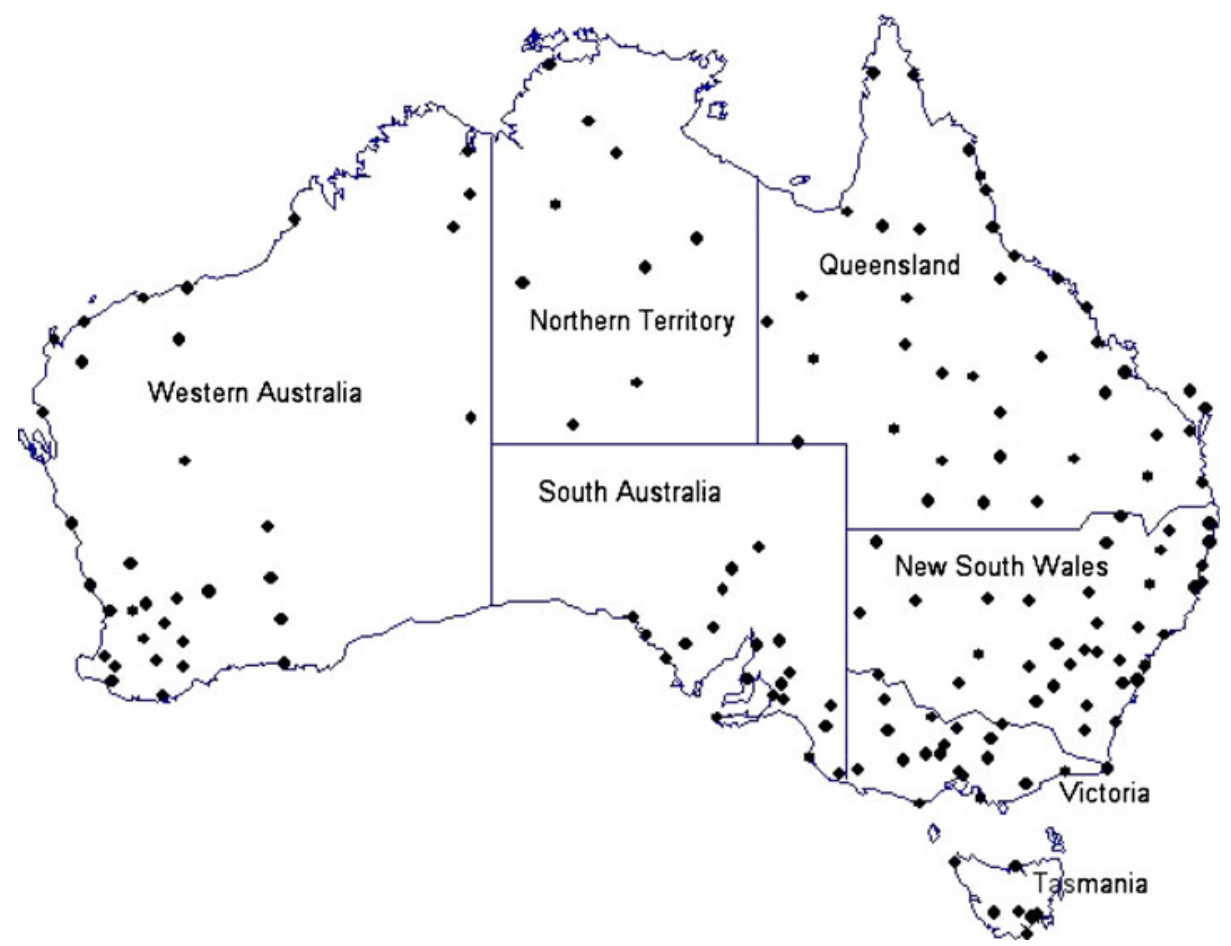

Fig. 3 Location of the 165 stations comprising the high-quality TCA dataset

\section{Identification of data inhomogeneities}

Climate data inhomogeneities are discontinuities or biases in a historical record caused by changes made to the way the data were recorded. Common sources of inhomogeneity in climate data series include (for example) site moves, instrument changes and changes in instrument exposure, or changes in observing practices. The impact of these inhomogeneities on the climate record can be as large as genuine climate shifts, and consequently they need to be eliminated, or at least minimised, before trends can be meaningfully examined. For total cloud amount, potential sources of discontinuities are perhaps smaller than for instrumental records, being largely limited to changes in observer practices. However, the potential for large discontinuities exists due to the subjective nature of the recordings.

Several Australian high-quality (homogenised) climate datasets have been developed to identify, monitor and attribute changes in elements such as rainfall (Lavery et al. 1992), temperature (Torok and Nicholls 1996; Della-Marta et al. 2004) and pan evaporation (Jovanovic et al. 2008). These datasets have been produced using a variety of quality control and correction techniques. The general approach to the rehabilitation of the Australian TCA record follows that of these previous datasets.

Potential inhomogeneities in individual monthly 9 a.m. and 3 p.m. TCA data series were detected using a combination of station metadata and an objective statistical technique. The statistical technique was based on the comparison between 
a candidate data series (the series to be homogenised) and a reference series assumed to be free of discontinuities. A change in the difference between the two series over time was used to flag a potential discontinuity in the candidate series.

Monthly TCA reference series were created for each candidate series by interpolation from an objective spatial analysis (Barnes 1964; Koch et al. 1983) based on all series except the candidate. The weighting function was chosen on the basis of maximising the predictive power of the reference series by minimising the cross-validated error following Seaman (1989). This results in an optimal weighted average of neighbouring series being used as the reference. The contribution from a neighbouring series to the weighted average decreases as the distance from the candidate increases. An example of a candidate and reference series is given in Fig. 4 for Merredin.

Monthly difference timeseries (candidate series minus reference series) were then produced. Potential discontinuities in the candidate series could be identified visually as an abrupt step change (see Fig. 5 for an example), or a change in the trend of the difference timeseries. Change points in the difference timeseries were also identified objectively using the RHTestV2 software (Wang and Feng 2007) which is designed to detect multiple change points (mean-shifts) in a climate timeseries (Wang et al. 2007; Wang 2008).

To verify discontinuities identified visually and statistically, a thorough examination of all available metadata (station history information) was undertaken. This included archived station history files containing inspection reports and correspondence with observers, as well as records from an electronic metadata database covering the past decade. Opinions from experienced observers were also sought.

One of the main sources of inhomogeneity in the TCA data series was found to be a change in observer at co-operative stations. This is not surprising given that TCA is a subjective measure of sky cover (Dai et al. 2006; Palle and Butler 2002). Individual observers are likely to be consistent in their estimates of TCA (either overestimating or underestimating it), but there is often a systematic difference between estimates

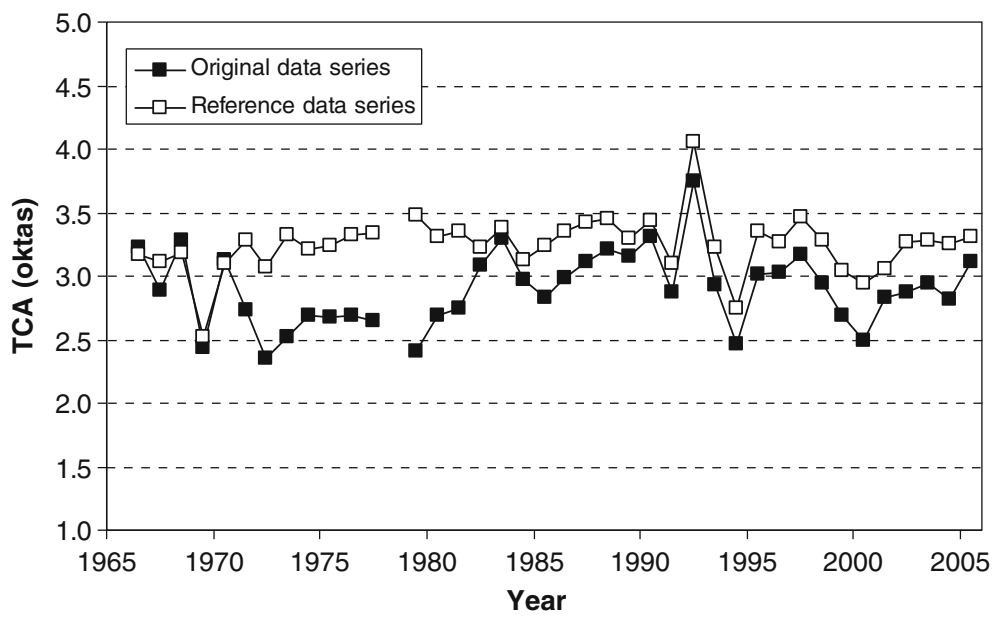

Fig. 4 Original and reference TCA series (annual mean 9 a.m. values) for Merredin (10092) 


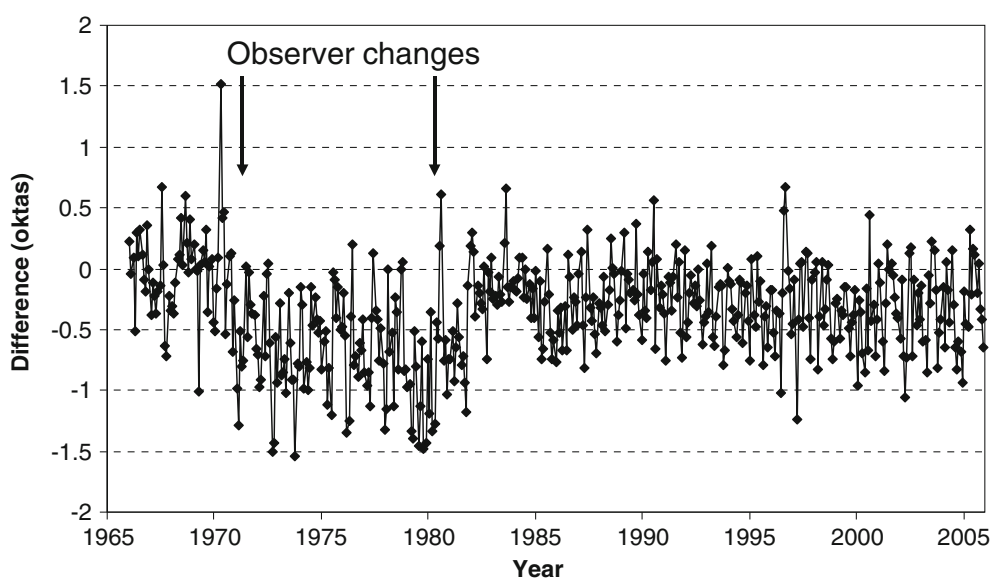

Fig. 5 Difference between monthly candidate and reference series of 9 a.m. TCA for Merredin (10092). Dates of observer changes are noted

from different observers. A change in observer at single observer stations was found to be the most common source of inhomogeneity (see Fig. 5 for an example). The overall frequency of changes in observer increased in the last two decades, possibly as a result of increased mobility of rural populations.

Of 165 stations selected for this study, only 42 are staffed by fully trained professional observers. The remainder are co-operative stations at which observations are usually performed by one non-professional observer with rather limited training.

The other main source of inhomogeneity in TCA data series was found to be major relocations, especially from poorly exposed sites (such as built-up areas or sites overgrown with vegetation) to more open sites (such as airports). Observers tend to extrapolate the cloud coverage for the part of the sky they cannot see. So if the proportion of sky obscured to the observer changes, so too can the estimate of cloud cover.

\section{Homogeneity adjustments}

To lessen the subjectivity of the homogenisation process, it was decided to only adjust data at change points identified by the objective statistical technique in both 9 a.m. and 3 p.m. data series, and confirmed by the metadata. Generally, when in doubt as to whether an adjustment was needed or not, the tendency was to not make an adjustment. However, due to gaps in station history information, there were a few cases where the objective test indicated inhomogeneities and adjustments were made, despite the fact that change points could not be confirmed by the metadata. These adjustments are noted in Appendix.

Verified discontinuities were adjusted in each monthly series using the difference in mean TCA from the discontinuity-free periods on either side of the change point. For each identified change point, adjustments were added from the beginning of the data series to that change point. In all data series, data were adjusted to the most 


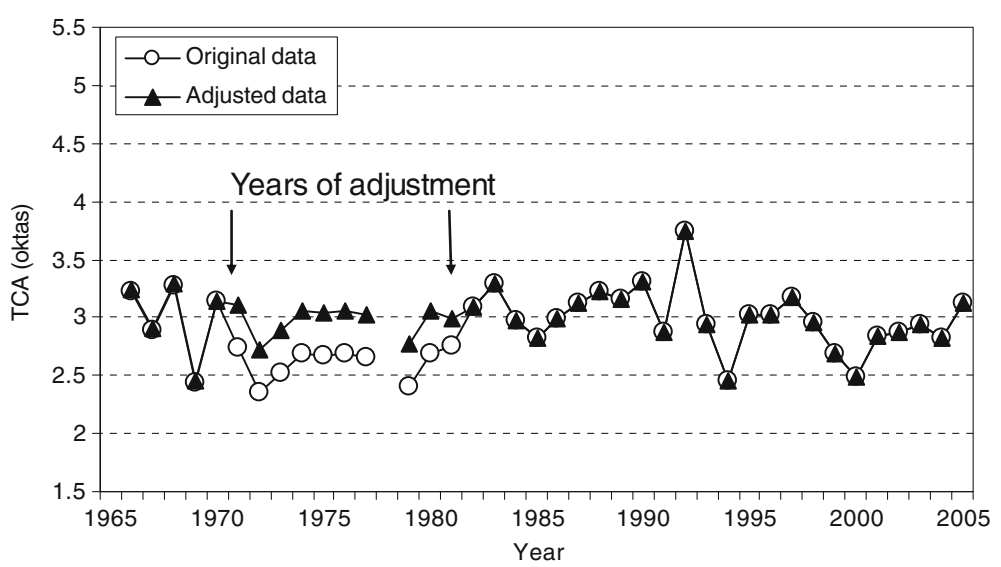

Fig. 6 Original and adjusted annual mean 9 a.m. TCA series for Merredin (10092). Dates of two inhomogeneities in the series are noted

recent homogenous period of the record. An example of the original and adjusted TCA series for Merredin, in south-west Western Australia, is shown in Fig. 6.

Identified change points and reasons for adjustments are shown in Appendix. Of 165 candidate stations, 96 required adjustment for detected inhomogeneities. Most stations which were found to be inhomogeneous required 1 or 2 adjustments, with several requiring 3 adjustments and 2 stations requiring 4 adjustments. Adjustments were mostly between 5 and $35 \%$ of the mean annual TCA (an average of $13.4 \%$ for morning and $12.8 \%$ for afternoon TCA).

\section{Daylight savings time adjustments}

Due to a diurnal cycle in TCA, the introduction of daylight saving time (DST) in some States of Australia was found to introduce small discontinuities in the 9 a.m. and 3 p.m. data series. During DST, observations in affected States are made $1 \mathrm{~h}$ earlier than the local standard time (LST). So, 9 a.m. (local DST time) observations are actually 8 a.m. LST observations, while 3 p.m. (local DST time) observations are actually at 2 p.m. LST. As a result, the introduction of DST did introduce small shifts in the 9 a.m. and 3 p.m. TCA series.

DST has been adopted sporadically in some States in the past, and at differing times of the year throughout the length of the record. DST was introduced in Tasmania in October 1967, in New South Wales, the Australian Capital Territory, Victoria and South Australia in October 1971, ${ }^{2}$ while in Western Australia it was introduced in December 2007. In the post-1957 period it has never been adopted in

\footnotetext{
${ }^{2}$ In New South Wales, Australian Capital Territory, Victoria and South Australia, DST was introduced in October 1971, but observations at different stations were taken at different times (e.g. 8, 9 or $10 \mathrm{am}$ local standard time for morning observations). Consequently, these data were not retrieved from the database. In mentioned states, as well as in Tasmania, TCA data were adjusted for DST from October 1972.
} 
the Northern Territory, while in Queensland it was adopted for only a short period from 1989 to 1992. Typically, DST starts in October and ceases in late March or, in recent years, early April (for more information on implementation dates of DST see: http://www.bom.gov.au/climate/averages/tables/dst_times.shtml).

Some stations across Australia perform three-hourly cloud observations. The diurnal cycle in TCA was estimated using stations that have at least the 6 a.m., 9 a.m., 12 p.m. and 3 p.m. TCA observations. Of 165 candidate stations, 87 stations across Australia fulfilled this requirement. For each station, a cubic spline was fitted to the 1990-2005 three-hourly climatology of TCA, in order to estimate the diurnal cycle in TCA from 6 a.m. to 6 p.m. for each calendar month. The hourly difference between daylight savings and standard time was found to be reasonably insensitive to the choice of model fitted to the hourly data. Depending on the amount of available data, the diurnal cycle for each station was determined using either daylight savings observations only, standard time observations only, or all available observations. An example of the hourly climatology of TCA is shown in Fig. 7a for Mildura in inland Victoria for the month of January.

The monthly climatological difference in TCA calculated between 8 a.m. and 9 a.m., and 2 p.m. and 3 p.m., was then calculated from the interpolated diurnal cycle. On average, these differences were an order of magnitude smaller than mean monthly TCA. Despite these differences being small it was decided to correct all station series for DST bias. Consequently, spatial analyses of the monthly climatological differences in morning (9 a.m.-8 a.m.) and afternoon (3 p.m.-2 p.m.) TCA were produced using the Barnes spatial interpolation (Barnes 1964; Koch et al. 1983).

In summer months there is a climatological increase in TCA from 8 a.m. to 9 a.m. for northern Victoria, most of New South Wales except the coastal areas, and most of Queensland and Tasmania (see Fig. 7b for January). In the remaining parts of the country there is a predominant decrease in cloudiness over this time of the day. In the afternoon, there is a general increase in TCA from 2 p.m. to 3 p.m. over most of Australia in summer months with the exception of narrow areas along the southern and eastern coast (see Fig. 7c for January). Consequently, the introduction of DST has resulted in a slight negative bias in the 3 p.m. TCA timeseries for most stations post-1972, with smaller negative (positive) biases in the eastern (western) Australian 9 a.m. TCA timeseries.

Monthly DST adjustments for each station were computed by interpolating from the analysed grids of climatological DST adjustment. The morning and afternoon monthly DST adjustments were weighted by the fraction of the month during which observations were taken in DST time. For example, the fraction of the month affected by DST observations for November to February in Victoria and NSW in most years is 1 (i.e. all days in the month have DST observations), while the fraction of the month with DST observations for October, March and April, varies between 0 and 1, depending on the start and end dates of DST. For Queensland and Western Australia, the fraction of the month affected by DST observations is mostly 0 , since DST has rarely been applied in those states. DST adjustments calculated in this way were added to monthly time-series of candidate stations in affected states and this was the final step in creating a high-quality monthly 9 a.m. and 3 p.m. TCA data series. 
(a)

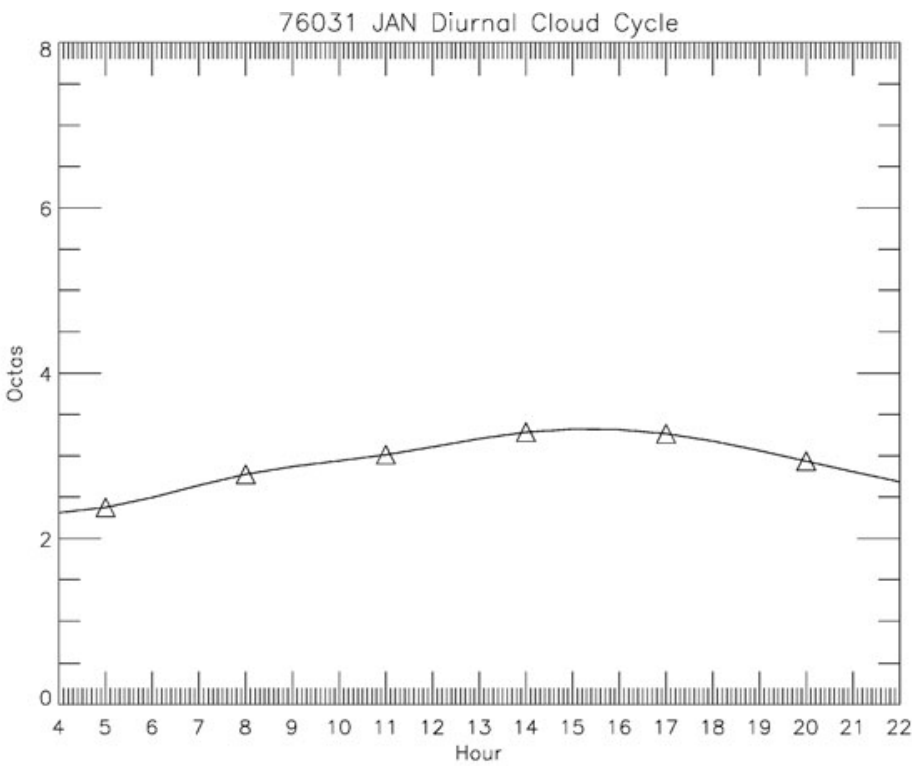

(b)

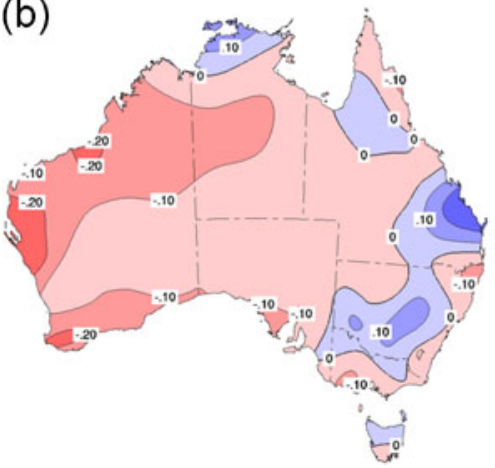

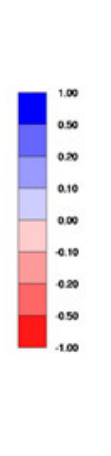

(c)

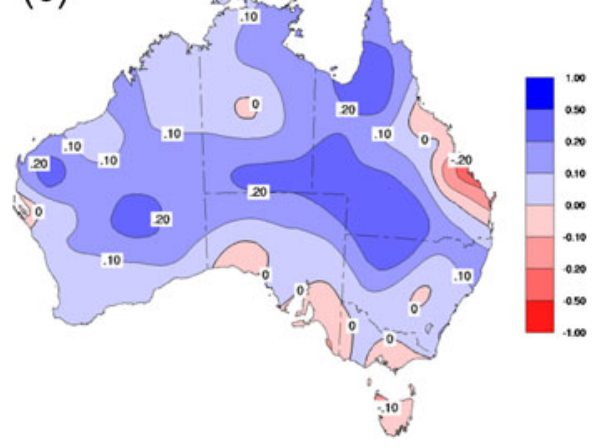

Fig. 7 a Diurnal cycle in TCA for January using Standard Time observations for Mildura 76031 and maps of climatological difference in $\mathbf{b} 8$ a.m. and 9 a.m. and $\mathbf{c} 2$ p.m. and 3 p.m. TCA for January. Units are oktas

\section{The new Australian high-quality TCA dataset}

The high-quality TCA dataset includes homogenised monthly 9 a.m., 3 p.m. and "daytime" TCA records for 165 locations across Australia, with most records starting around 1957. Monthly daytime TCA series were calculated as the simple averages of the monthly 9 a.m. and 3 p.m. series. Jones and Henderson-Sellers (1992) found that the mean of TCA at these two observation times is a good approximation of the mean daytime TCA. For simplicity, most analyses below are based on only the daytime TCA series. Generally, analyses of the 9 a.m. and 3 p.m. TCA series provide similar results to the daytime series. 
The Australian high-quality TCA dataset is available for download at: http://www. bom.gov.au/climate/change/datasets/datasets.shtml.

\section{Climatology}

Monthly normals of TCA were generated for each of the homogenised TCA series over the 1983 to 2006 base period. ${ }^{3}$ These were then used to create climatological maps of annual and seasonal daytime cloud maps (Fig. 8).

The annual TCA climatology shows a minimum of less than 2 oktas in northeast South Australia, increasing toward maxima of more than 4 oktas in the far southwest of Western Australia, Victoria, Tasmania, the Top End of the Northern Territory and coastal regions of northern Queensland and New South Wales. However, topographic influences from the Great Dividing Range are not captured well, partly due to the lack of stations at higher elevations in the dataset. Climatological maps of TCA for autumn and spring are qualitatively similar to the annual distribution, while the summer climatology shows high TCA across the tropics, and winter shows high TCA across the far south. These patterns compare well with climatological patterns of rainfall (see comparison with rainfall, below) and can be readily explained by seasonal weather patterns around the country.

The high spatial coherence in the climatological maps provides some validation that the subjectivity in individual data measurements at individual locations has largely been removed through homogenisation and averaging. It also means that it is likely to be reasonable to interpolate normals of TCA recorded at single points across regions without observations.

\section{Trend analysis}

Long-term trend values were calculated for each high-quality TCA series over the most common period of record (1957-2007). As with the climate normal values, these were then analysed onto a regular grid to produce spatial maps of trends in annual and seasonal daytime TCA across Australia (Fig. 9). The patterns of trends in morning and afternoon TCA (not shown) are generally very similar to those of daytime cloud. Trends calculated for individual station annual mean daytime TCA are provided in Appendix.

The map of post-1957 trends in annual daytime TCA (Fig. 9a) shows increasing trends over most inland and northern parts, with areas of decreasing cloud along the eastern seaboard, across much of the south and in the far west. Decreasing TCA is also apparent in the far northwest, which is somewhat surprising, given a marked increase in annual rainfall in the region over the same period (Smith 2004; Jakob 2006).

Maps of seasonal TCA trends over the past half-century (Fig. 9b-e) reveal that changes during autumn and spring largely follow those for the annual timescale. Winter shows weak but widespread declines in TCA across the west and south,

\footnotetext{
${ }^{3} 1983-2006$ was used as a base period to enable comparison with the available satellite cloud climatology.
} 


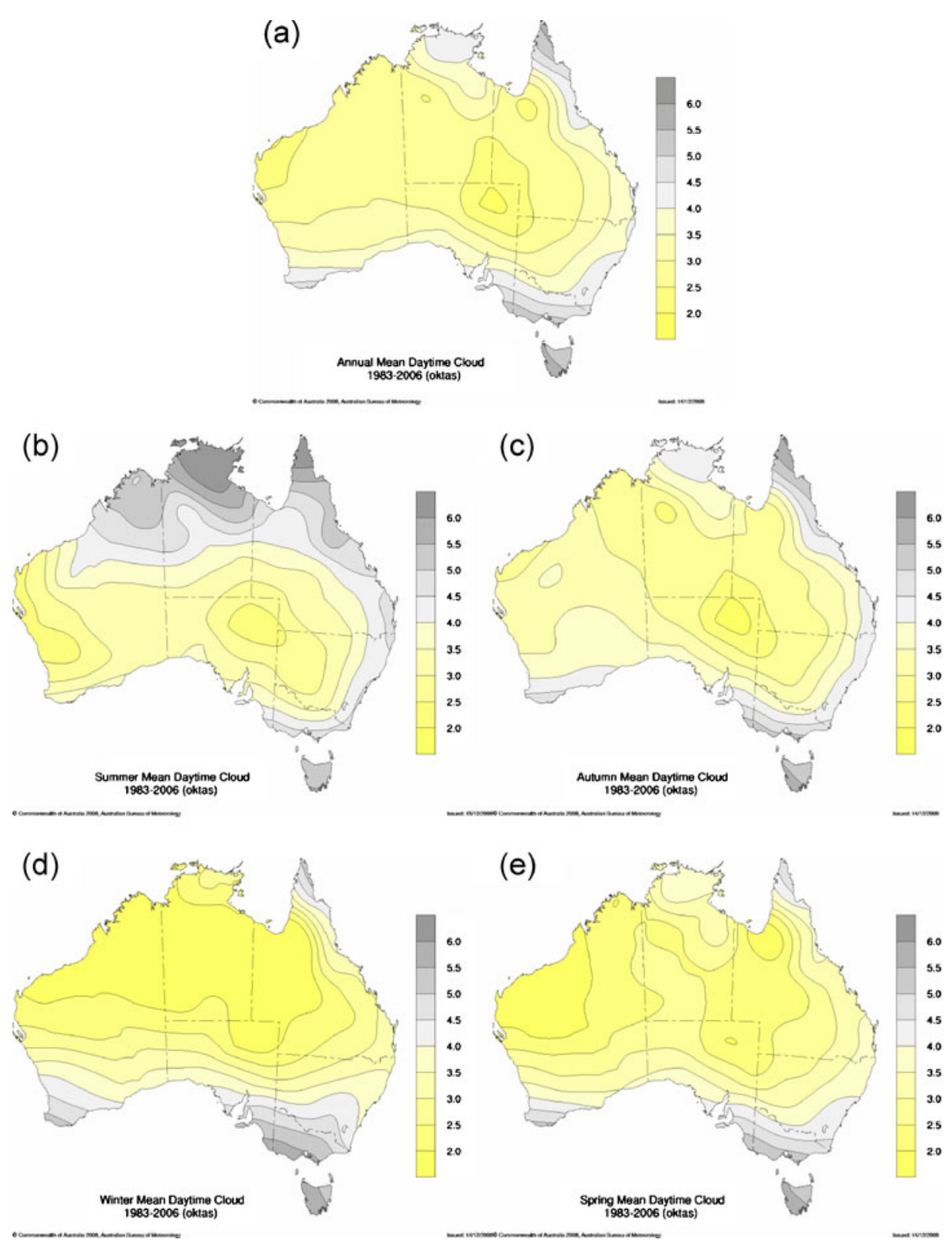

Fig. 8 Maps of 1983-2006 mean a annual, b summer, c autumn, d winter and e spring daytime TCA

with coherent increases in the northeast, while summer shows widespread increases, including over the northwest. This suggests that increased wet-season rainfall associated with increased summer TCA in the northwest has resulted in an increase in annual rainfall despite declines in TCA during the dry season.

To investigate variability at the continental scale, timeseries of all-Australian annual and seasonal mean TCA were generated by averaging over gridded analyses 


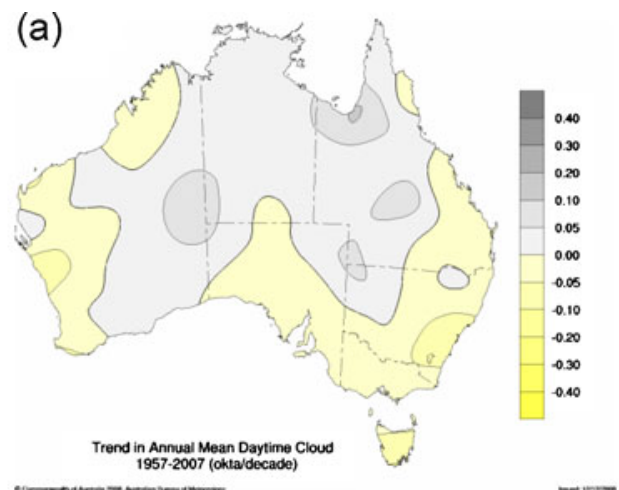

(b)

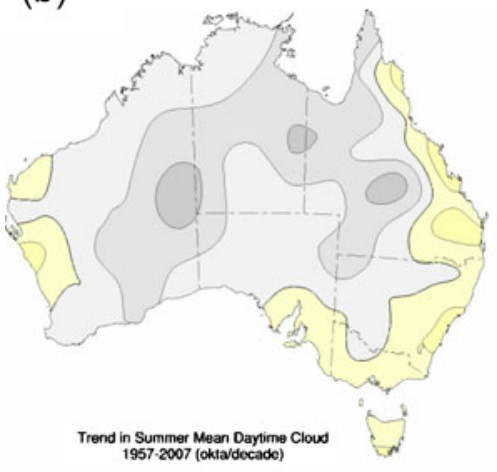

(d)

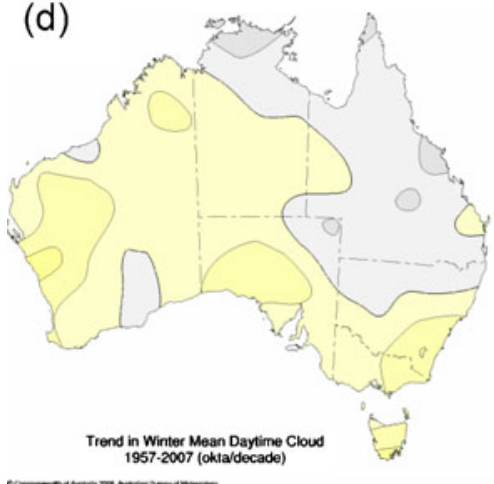

(c)

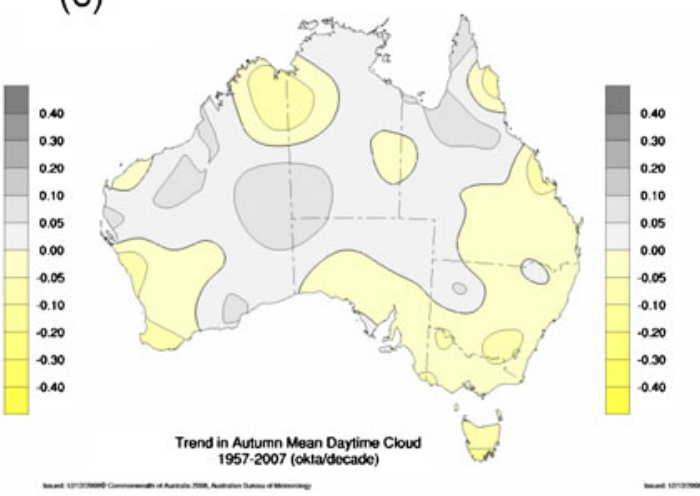

(e)

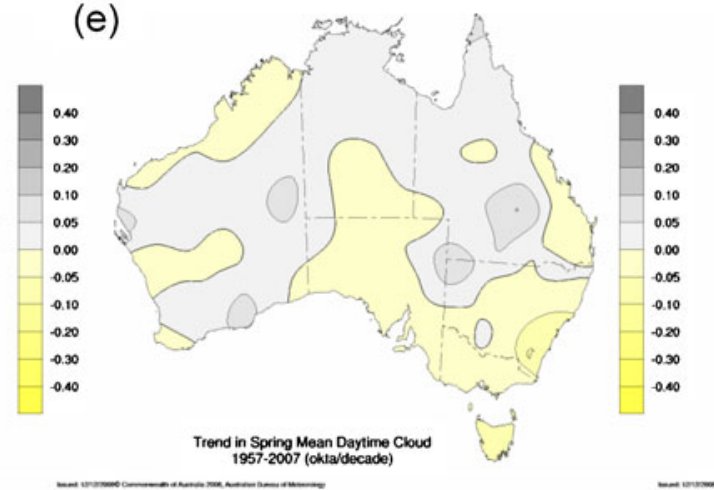

Fig. 9 Maps of 1957-2007 trends in a annual, b summer, c autumn, d winter and e spring daytime TCA

of the station series (Fig. 10). Australian annual mean values of 3 p.m. TCA are approximately 0.5 okta greater than those for 9 a.m., reflecting the increase in TCA from morning to afternoon. Australian annual mean TCA timeseries are character- 


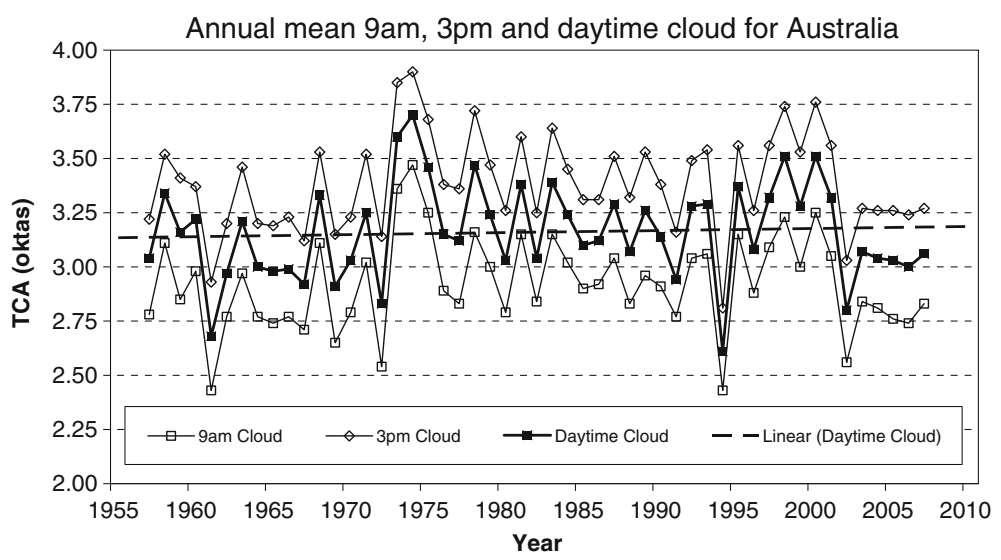

Fig. 10 Annual mean 9 a.m., 3 p.m. and daytime TCA for Australia

ized by high year-to-year variability, consistent with rainfall variability. Particularly low cloudiness is associated with the major El Niño drought years of 1972, 1994 and 2002. Warren et al. (2007) found that, in comparison to other continents, Australia has very large interannual variability of TCA, due to a strong influence from the El Niño-Southern Oscillation (ENSO).

Over the 1957-2007 period, the Australian annual daytime TCA shows a weak positive trend of $0.09 \mathrm{okta} /$ century. The trend is not statistically significant at the $95 \%$ level. Over a shorter 31 year period (1977-2007), the trend in Australian annual mean TCA is negative ( $-0.44 \mathrm{okta} / \mathrm{century})$ but also not statistically significant. Australian seasonal mean TCA series for the 1957-2007 period (not shown) have strongest trends for summer (an increase) and winter (a decrease), while spring and autumn trends are close to zero. No seasonal trends were statistically significant at the $95 \%$ level.

Comparison between TCA timeseries for the Australian region provided by Warren et al. (2007) and our results, for the common period (1971-1996), reveals negative trends of similar magnitude. This similarity occurs despite the fact that two analysis are based on different number of stations (74 and 165 respectively) and Warren et al. include neighboring Pacific Islands. On the more local scale differences in trends obtained from these two datasets should be expected due to the differences between datasets.

The recent years from 2002 through 2007 show an unusual prevalence of lower than average cloud cover across Australia. Large parts of Australia have experienced a protracted drought event over this period (BoM 2008) with record low inflows in a number of river systems in the southeast (MDBC 2007). These cloud data suggest that this long drought event has been accompanied by persistently below average cloudiness, which is likely to have increased potential evaporation, thereby exacerbating the effects of the low rainfall. 


\section{Comparison with rainfall}

Due to their obvious physical relationship, it is reasonable to expect a strong link between TCA and rainfall. The maps of annual and seasonal TCA normals (Fig. 8) are indeed highly consistent with maps of rainfall normals (BoM 2000). The highquality TCA network is sparse when compared to the rainfall network, and is unable to capture the topographic features evident in the rainfall climatologies. Nevertheless, the broadscale consistency between rainfall and TCA climatologies increases the confidence that the new high-quality TCA dataset is sufficiently dense to adequately describe the broadscale patterns of TCA over the Australian continent.

Comparisons between changes in TCA and changes in rainfall are also made, noting that cloud type, thickness or heights could all change independently of TCA, resulting in a change in the amount of rainfall for a given TCA. Nevertheless, the spatial patterns of trends in annual data over the past half-century are generally consistent between TCA (Fig. 9a) and rainfall (see http://www.bom.gov.au/climate/change for post-1960 trend). Both show general increases in the interior and decreases in the far southwest, southeast and along the eastern seaboard. However, as already mentioned, an area of apparent inconsistency is evident in the far northwest.

Northwest Australia is a data sparse region of the continent. The analysis of TCA trends in the region is based on only a few stations. Consequently, patterns of change are less reliable compared to those in data rich areas. Nevertheless, it is unlikely that undetected inhomogeneities or data gaps could account for the declining annual values in the northwest.

The decline in annual TCA in the far northwest is mostly due to declines during autumn and spring, with winter showing little trend and summer showing an increase. The northwest of Australia has a monsoonal climate with most rain falling during the summer period. It is during summer that most of the increase in rainfall has occurred and this increase has been associated with an increase in cloudiness. Also, Jakob et al. (2009) show that most rainfall in northwest Australia falls at night due to the interaction between tropical convection and the heat low of the region. Consequently, it is possible that nighttime rainfall may have increased in the northwest independently of the changes in daytime cloud shown here.

Seasonal trends since 1957 are less consistent between TCA (Fig. 9b-e) and rainfall (see http://www.bom.gov.au/climate/change for post-1960 trends) than for annual trends. However, there are some important areas of agreement. During summer both show declines along the far west and east coasts, with mostly increases in the remainder of Australia. Patterns of change during autumn agree across the south, but TCA shows a decline in the northwest despite a rainfall increase. However, it is possible that increased autumn rain in the northwest could result from increases during early autumn, even if there is a decline in TCA across the season as a whole. Decreasing TCA in the southwest during autumn and winter is consistent with decreasing rainfall in the region during these seasons, mostly from the mid-1960s (Timbal et al. 2006). Both variables show mostly weak changes during

Fig. 11 Timeseries of Australian annual mean daytime TCA and annual a rainfall total and $\mathbf{c}$ DTR. Note inverse scale for DTR. Corresponding scatter diagrams are also shown for b rainfall against TCA and $\mathbf{d}$ DTR against TCA 
(a)

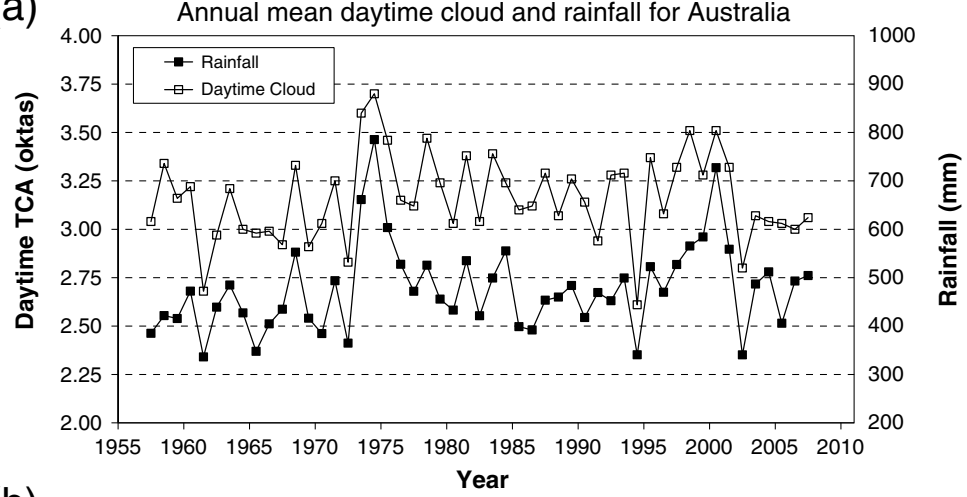

(b)

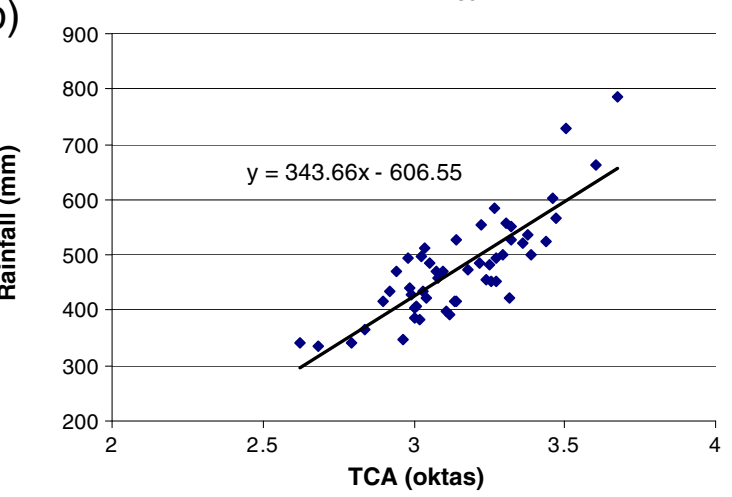

(C) Annual mean daytime cloud and DTR for Australia

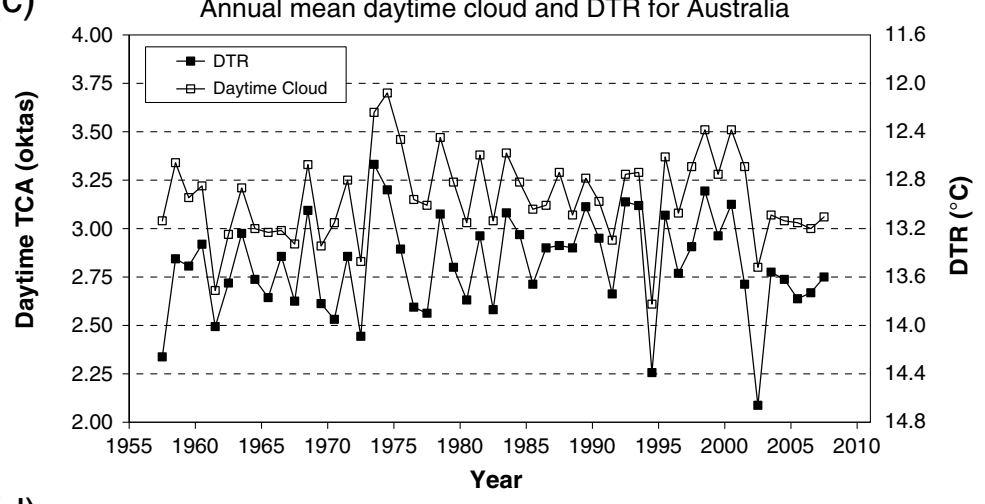

(d)

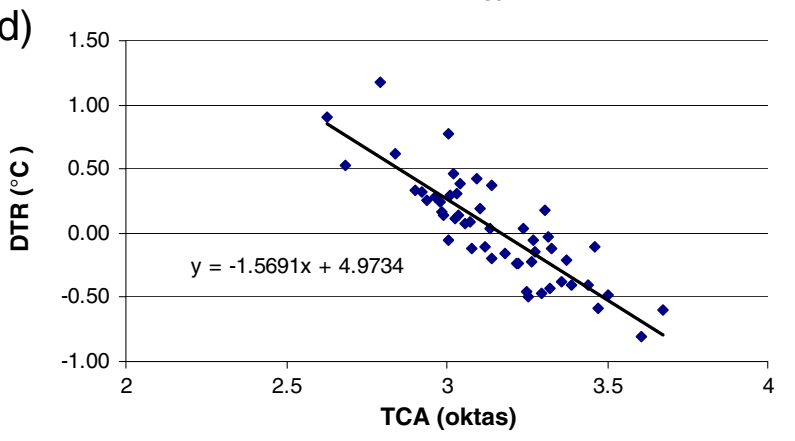


Table 1 Correlation between Australian annual and seasonal mean TCA and rainfall, temperatures (maximum, mean, minimum, DTR), pan evaporation and the Southern Oscillation Index (SOI). Correlations are calculated over 1957-2007, except for correlations between TCA and pan evaporation which are restricted to 1970-2007 due to the shortness of the pan evaporation record

\begin{tabular}{llllclll}
\hline & $\begin{array}{l}\text { TCA and } \\
\text { rainfall }\end{array}$ & $\begin{array}{l}\text { TCA and } \\
\text { max T }\end{array}$ & $\begin{array}{l}\text { TCA and } \\
\text { mean T }\end{array}$ & $\begin{array}{l}\text { TCA and } \\
\text { min T }\end{array}$ & $\begin{array}{l}\text { TCA and } \\
\text { DTR }\end{array}$ & $\begin{array}{l}\text { TCA and } \\
\text { Pan Evap }\end{array}$ & $\begin{array}{l}\text { TCA and } \\
\text { SOI }\end{array}$ \\
\hline Annual & 0.82 & -0.55 & -0.23 & 0.18 & -0.85 & -0.72 & 0.36 \\
Summer & 0.85 & -0.61 & -0.35 & 0.15 & -0.87 & -0.83 & 0.46 \\
Autumn & 0.79 & -0.48 & -0.05 & 0.48 & -0.90 & -0.66 & 0.32 \\
Winter & 0.84 & -0.48 & 0.10 & 0.59 & -0.87 & -0.59 & 0.43 \\
Spring & 0.85 & -0.69 & -0.50 & -0.14 & -0.87 & -0.79 & 0.43 \\
\hline
\end{tabular}

spring, although a decline in spring TCA on the southern New South Wales coast corresponds well to a region of strong rainfall decline.

Interannual variations in timeseries of Australian annual mean daytime TCA and rainfall (Fig. 11a) are highly consistent, with both showing spikes during the first half of 1970 s and persistently low values since 2002. Annual mean daytime TCA values for 2003-2007 are similar to those recorded during 1964-1967, yet the annual mean rainfall values of the later period are mostly higher than those of the earlier period. This is probably due to the low TCA values in recent years being due to drought conditions across southern Australia, with above average northern Australian rainfall and TCA during summer resulting in a higher proportion of convective rainfall in the overall Australian mean and hence more rainfall for a given TCA value.

Correlations between Australian mean annual and seasonal TCA and rainfall are given in Table 1. A strong correlation exists between annual TCA and precipitation at the national scale (correlation coefficient $=0.82$ ). Seasonal correlations show the relationship to be strong throughout the year. A scatter diagram between Australian annual mean TCA and annual rainfall totals is shown in Fig. 11b. Based on linear regression, a decrease in TCA of 0.1 okta is accompanied by a decrease in Australian mean rainfall of about $35 \mathrm{~mm}$.

As for rainfall, annual variations in TCA are related to the El Niño-Southern Oscillation (ENSO), with a correlation coefficient of +0.36 (significant at the $5 \%$ level) between Australian annual mean daytime TCA and annual Southern Oscillation Index (Table 1). This correlation with cloud cover partly explains the correlation between DTR and ENSO as described by Jones and Trewin (2000). The correlation between TCA and SOI is weakest during autumn.

\section{Comparison with temperature}

A strong inverse relationship is expected between TCA and DTR because clouds act both to hinder daytime warming, and to reduce overnight cooling. The map of trends in annual mean daytime TCA since 1957 (Fig. 9a) shows some consistency with the annual mean DTR trend map over the same period (see http://www.bom. gov.au/climate/change for post-1960 trends), with mostly increases in DTR over southern Australia and decreases in the north. Interestingly, a region of increasing annual mean DTR is analysed in the northwest, consistent with the decline in annual $\mathrm{TCA}$ in this region. 
Figure 11c and d show a strong correlation between timeseries of Australian annual mean daytime TCA and DTR (correlation coefficient $=-0.85$ ). This relationship is strong during all seasons (Table 1). Generally, the inverse relationship between TCA and daily maximum temperatures is stronger than the relationship between TCA and daily minimum temperatures. The correlation between Australian seasonal TCA and maximum temperature is moderately strong throughout the year. However, the link between Australian TCA and minimum temperature is strong during winter, and moderate during autumn, with little correlation during spring and summer. Jones and Trewin (2000) and Power et al. (1998) have previously noted complex seasonal variations in the relationship between Australian maximum and minimum temperatures, rainfall and cloud cover. During the warmer months the increased warmth of daytime temperatures associated with decreased rainfall and cloud cover fully compensates for increases in DTR, whereas in the cooler months this does not occur.

\section{Comparison with pan evaporation}

As evaporation is dependent on the amount of incoming solar radiation, an inverse relationship is expected between TCA and pan evaporation (Morton 1983). Correlations between all-Australian mean TCA and pan evaporation indicate that their interannual variations are strongly opposed (Table 1). This relationship is strongest during spring and summer.

Jovanovic et al. (2008) found a near-zero trend in all-Australian pan evaporation over 1970-2005, despite a clear signal of atmospheric warming over this time. It has been suggested that decreases in solar radiation, or a decline in mean wind speed, may have offset the influence of a warmer atmosphere and reduced relative humidity. Since 1970, the all-Australian TCA shows a slight decline, indicating that cloud cover increases (and hence a decline in solar radiation) is not a viable explanation for the near-zero pan evaporation trend. Rayner (2007) suggested that a decline in wind speed has driven many of the local pan evaporation changes and McVicar et al. (2008) have indeed shown a decline in Australian wind speeds over the 1975-2006 period.

\section{Comparison with satellite data}

In this section we are using data from the International Satellite Cloud Climatology Project (ISCCP, Rossow and Schiffer 1999) to assess and validate our results based on surface observations. An in-depth assessment of the satellite data to judge their potential use as a substitute for surface observations is outside the scope of this paper but we note that satellite derived cloud cover can offer many potential advantages over surface observations including continuous spatial coverage, better temporal coverage, and consistent sampling through the day and night. The need to look to remotely sensed data for monitoring climate is made more urgent by the rapid reduction in surface networks as a result of automation. There are however some potential issues with satellite data due to changes in satellite viewing geometry, as discussed by Evan et al. (2007). For Australia, we judge these changes as generally insignificant with the possible exception of the most southerly parts of Australia. 

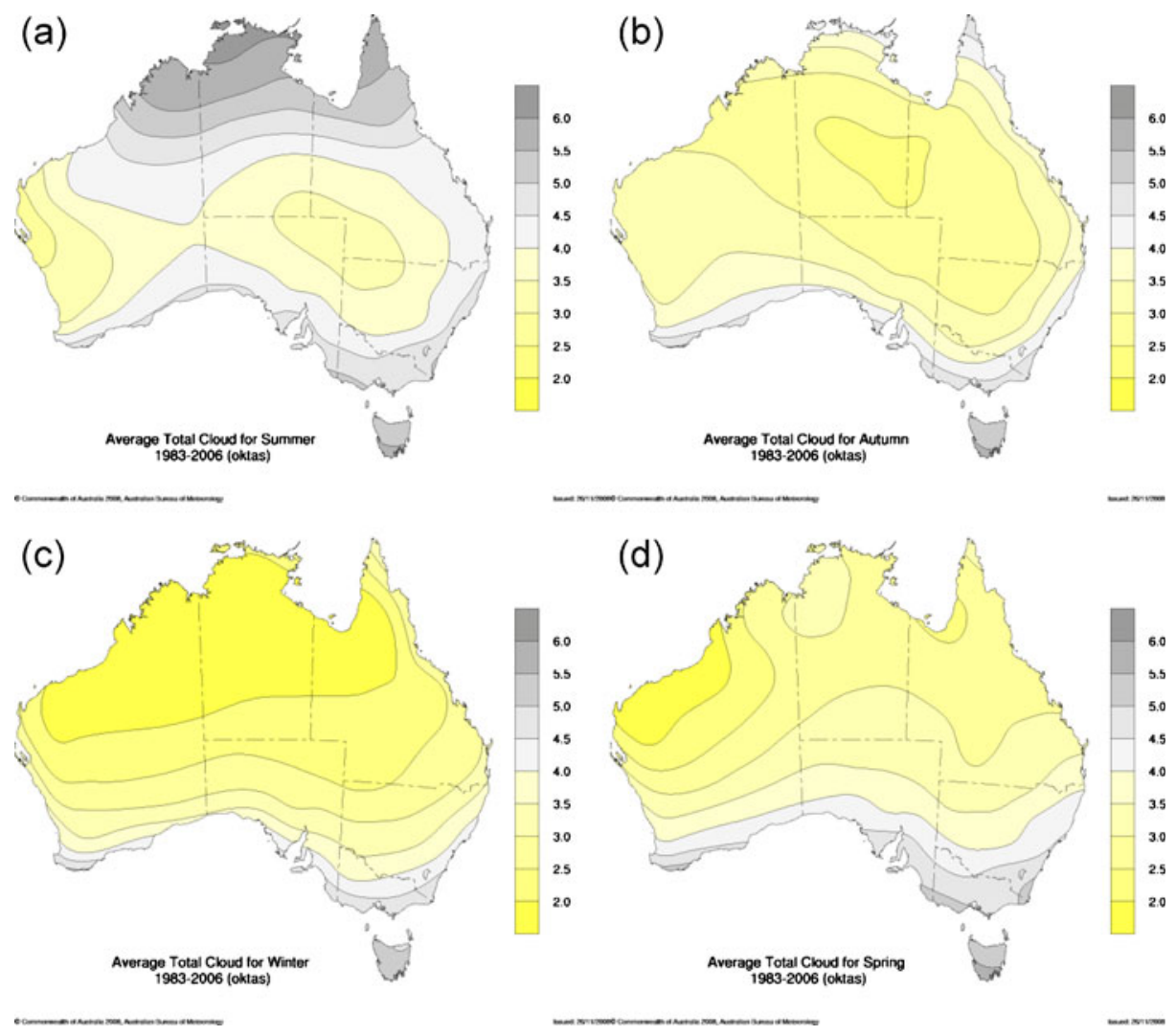

Fig. 12 Maps of 1983-2006 mean a summer, b autumn, c winter and d spring cloud cover (oktas) derived from 3-hourly satellite observations (International Satellite Cloud Climatology Project)

From the large number of ISCCP products we chose 3-hourly cloud cover (in percent). For comparison with surface observations, we converted these values to okta and derived regular grids with a resolution of 2.5 by $2.5^{\circ}$. There are three differences in particular which could lead to differences in climatologies and trends of total cloud cover derived from satellite data and surface observations respectively:

- The satellite derived estimates are available at a much coarser resolution, which may lead to inadequate spatial sampling of maxima and minima in cloud cover.

- Satellite derived cloud cover is based on 3-hourly observations (including nighttime) while surface observations are derived from 9 a.m. and 3 p.m. observations only.

- The horizontal direction in which observations are taken may lead to more emphasis on high clouds in satellite derived estimates when compared to surface observations.

Figure 12 shows climatological maps of seasonal cloud cover derived from satellite data for the available period of record (1983-2006). These maps show broadly similar patterns; in particular both reflect increased cloud cover across the north during summer (Fig. 8b-e). However, variations on smaller spatial scales that are 
notable in the maps derived from surface observations are not resolved in the maps based on cloud satellite data. The satellite derived data tend to indicate higher total cloud cover in inland parts throughout the year, and across southern areas during summer where differences are as large as 0.5 to 1 okta. A possible explanation for the difference is the under-reporting of thin, high-level clouds by human observers. We note that there is a lack of agreement in estimates of total cloud cover for the south of Australia. These differences are especially apparent for the summer and winter season. A detailed assessment of causes for these differences has yet to be undertaken.

Figure 13 shows maps of trends in seasonal cloudiness over the Australian region for the 1983-2006 period, derived from the ISCCP data. For comparison purposes, Fig. 14 shows trends from the surface-observed TCA dataset over the same period. The maps of 24 year trends in the TCA dataset are noisier than for the full dataset (1957-2007) (Fig. 9) as the record is shorter and trends are more susceptible to outliers. The station based TCA analyses tend to show more detail than the ISCCP data as the trends are calculated at stations and then mapped, meaning local affects are evident. In contrast, the ISCCP data are on a regular grid with a $2.5^{\circ} \times 2.5^{\circ}$ spacing effectively summarizing trends over very large boxes.
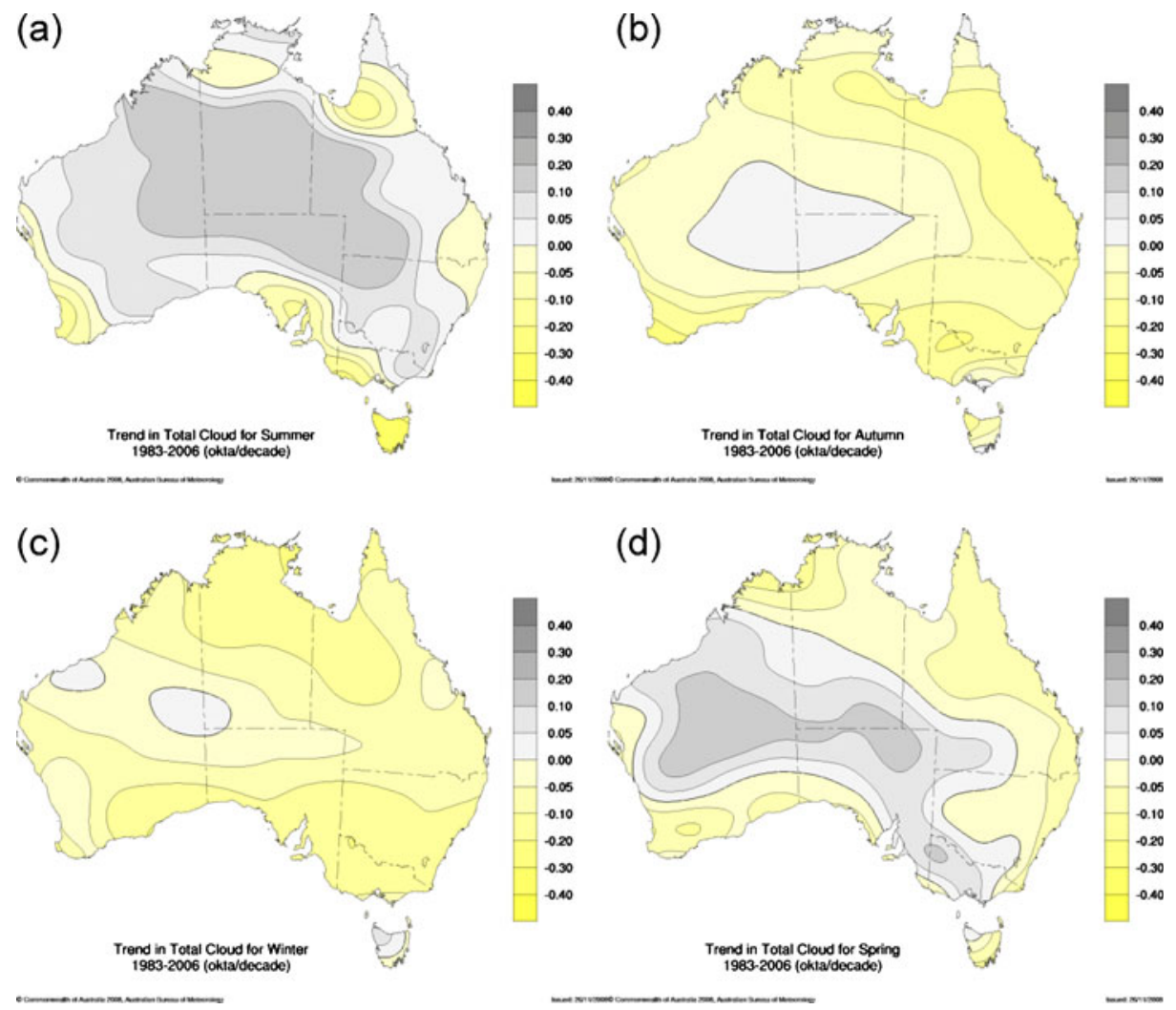

Fig. 13 Maps of 1983-2006 trends in a summer, b autumn, c winter and $\mathbf{d}$ spring cloud cover (oktas) derived from 3-hourly satellite observations (International Satellite Cloud Climatology Project) 

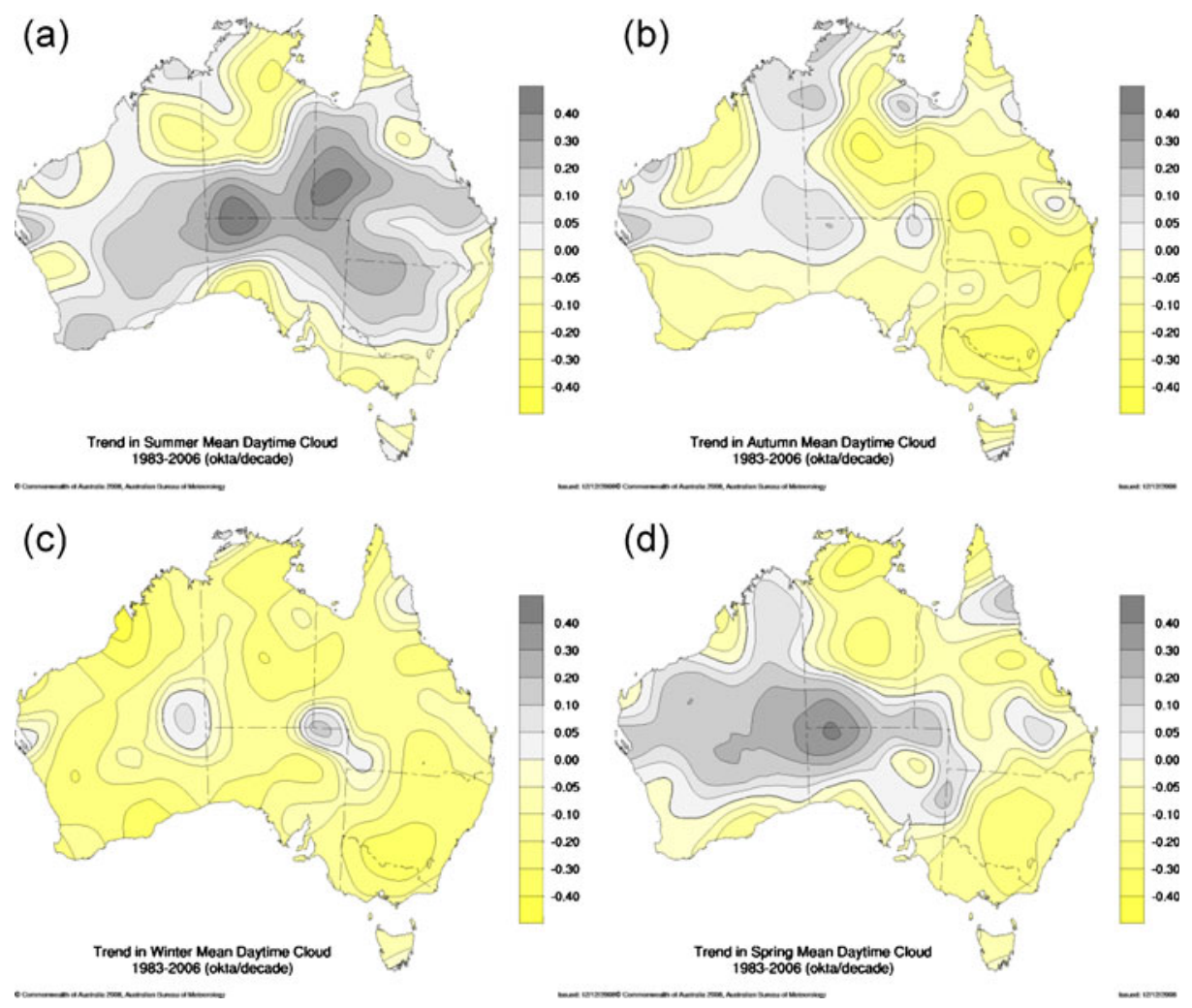

Fig. 14 Maps of 1983-2006 trends in a summer, b autumn, c winter and $\mathbf{d}$ spring daytime TCA from station data

Trends during spring are remarkably consistent, with both datasets showing a decline in cloudiness across the southern fringe of Australia, and widespread regions of decline across the north and east. Autumn and winter trends show widespread declines across the continent in both datasets. Summer trends are consistent across most of the continent, except in the northwest. The satellite data shows no decline in summer cloud in the northwest. Assuming both datasets are providing realistic trends, this suggests that the northwest has experienced an increase in nocturnal cloudiness during summer which is undetected by the daytime TCA. Generally the pattern of trends in the ISCCP is smoother than the TCA data, possibly due to residual inhomogeneities in the TCA series, but possibly also partly due to differences in the spatial analysis techniques used.

Figure 15 shows a comparison between the timeseries of Australian annual mean daytime TCA and cloud amount derived from 3-hourly satellite (ISCCP) data. The series are consistent, particularly prior to 2000. This is despite local inconsistencies and different data resolution in these data. The apparent divergence in the cloud series since 2000 is possibly a result of an inhomogenity in the ISCCP data over Australia, since the surface TCA relationships to rainfall and diurnal temperature over Australia have remained constant over this period (Fig. 11). Alternatively, it could suggest that recent years have experienced higher than average overnight cloud, particularly in the northwest of the continent, which is not captured in the 


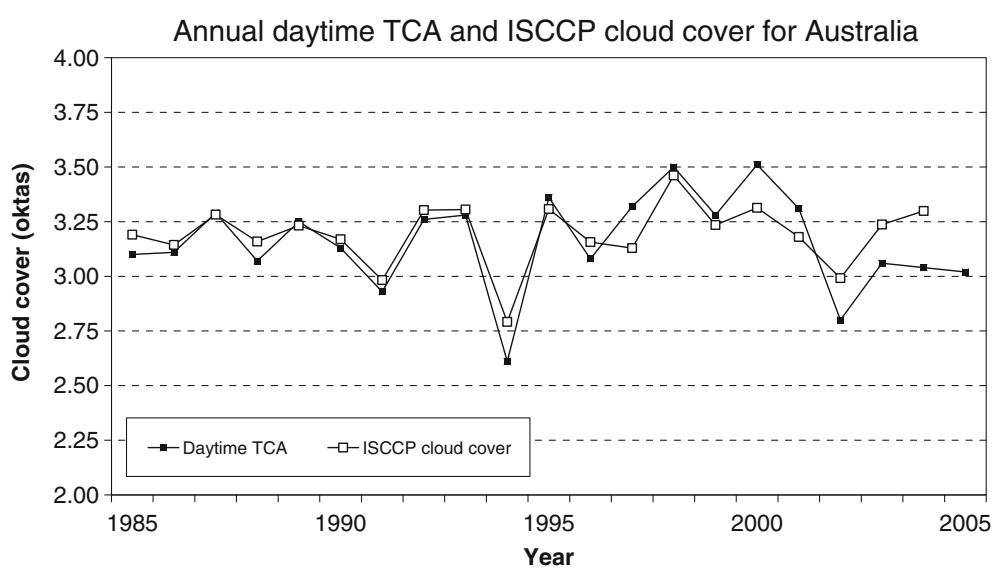

Fig. 15 Timeseries of Australian annual mean daytime TCA and cloud amount derived from 3-hourly satellite (ISCCP) data

daytime TCA values. In either case, this divergence warrants further investigation but is beyond the scope of this study.

The level of consistency in trends and normals provided by the TCA and ISCCP datasets was not guaranteed, given that they measure cloud amount in quite different ways: TCA is measured from below, while ISCCP data from above; TCA is based on a relatively coarse in-situ network, while ISCCP data has a continuous spatial coverage; they have different viewing angles; TCA estimates are rounded to oktas with an upward bias for values less than one and a downward bias for values between 7 and 8 , while ISCCP data is measured as a continuous percentage; and daytime TCA is based on only 9 a.m.and 3 p.m. observations, while the ISCCP dataset has coverage over $24 \mathrm{~h}$. We note that a more detailed comparison of observer and satellite derived TCA is required to properly explore this issue.

\section{Discussion and conclusions}

This study has resulted in the development of the first homogeneous cloud dataset for Australia. Five decades (1957-2007) of high-quality monthly TCA records have been produced across a total of 165 stations. Analysis of these data reveals that the Australian mean annual total cloud amount is characterised by high year-toyear variability. A contrast in trends across seasons and regions, coupled with high interannual variability, means that the national mean trends are small and not statistically significant.

At the local scale declines in TCA are observed in both the southeast and southwest of Australia, which reflect decreasing cloudiness during autumn, winter and to some extent spring. These changes have been accompanied by declines in rainfall over the same period. Central and northern Australia tends to show increased TCA since 1957, largely as a result of increasing trends in summer and autumn. While it is not surprising that TCA trends are closely correlated to rainfall trends, this agreement suggests that impact of decreasing trends in rainfall in the southeast 
and southwest are likely to be amplified by trends in potential evapotranspiration as a result of the decrease in cloud cover.

A strong positive correlation is found between all-Australian means of cloud amount and rainfall, while a strong negative correlation is found between mean cloud amount and diurnal temperature range. Although the distribution of the TCA network is not dense enough to fully capture topographic influences, the broadscale consistency between patterns of cloud, rainfall and DTR variations suggests that the new TCA dataset is able to describe the general patterns of change over Australia.

The TCA dataset developed here is probably not completely free from homogeneity problems, as it would be impossible to correct for all changes in observers. Also, the homogeneity adjustment process is partially subjective and sometimes based on incomplete metadata information. Nevertheless, this dataset represents the best available and longest data for monitoring changes in TCA over the Australian continent. The dataset will be used for operational monitoring of cloudiness within the Australian Bureau of Meteorology, and will enhance the understanding of how the hydrological cycle and weather patterns have changed over Australia in recent decades.

It would be valuable to have homogenised records of cloud heights and types to help explain some of the apparent inconsistencies between changes in cloud and rainfall. However, these measures are more problematic than TCA. Cloud heights and types from stations staffed by professional weather observers may be of sufficient quality, especially as many have weather balloon data available to verify cloud heights and thicknesses through the use of relative humidity observations. Further this would limit the network to less than 60 sites. It is unlikely that historical records of cloud heights and types from co-operative observers with limited meteorological training could be rehabilitated to the standard required for reliable analysis.

Out of 165 stations selected for the high-quality TCA dataset, 30 stations have digitised TCA records dating pre-1957 (with data starting generally in the 1930s and 1940s, but with some starting at the beginning of the twentieth century). Although there is a possibility of increasing the number of stations with longer time series, the general lack of metadata for the period before the late 1950s makes it impossible to extend the high-quality TCA dataset to the beginning of twentieth century using the methodology presented in this paper.

Favourable comparisons between surface and satellite measures of cloudiness suggest that satellites may ultimately provide the means for monitoring long-term changes in cloudiness over Australia. However, due to the relative shortness and homogeneity problems of the satellite record, a robust network of surface TCA observations will be required for many years to come.

Acknowledgements The authors would like to thank to Dr Blair Trewin and Mr Neil Plummer for their comments on earlier versions of the manuscript. Special thanks to Neil Plummer who commenced a previous, uncompleted high-quality TCA dataset for Australia, and to John Flannery for valuable comments about TCA observational practices. This research has been partially supported by the West Australian Department of Environment and Conservation under the Indian Ocean Climate Initiative Stage 3.

Open Access This article is distributed under the terms of the Creative Commons Attribution Noncommercial License which permits any noncommercial use, distribution, and reproduction in any medium, provided the original author(s) and source are credited. 


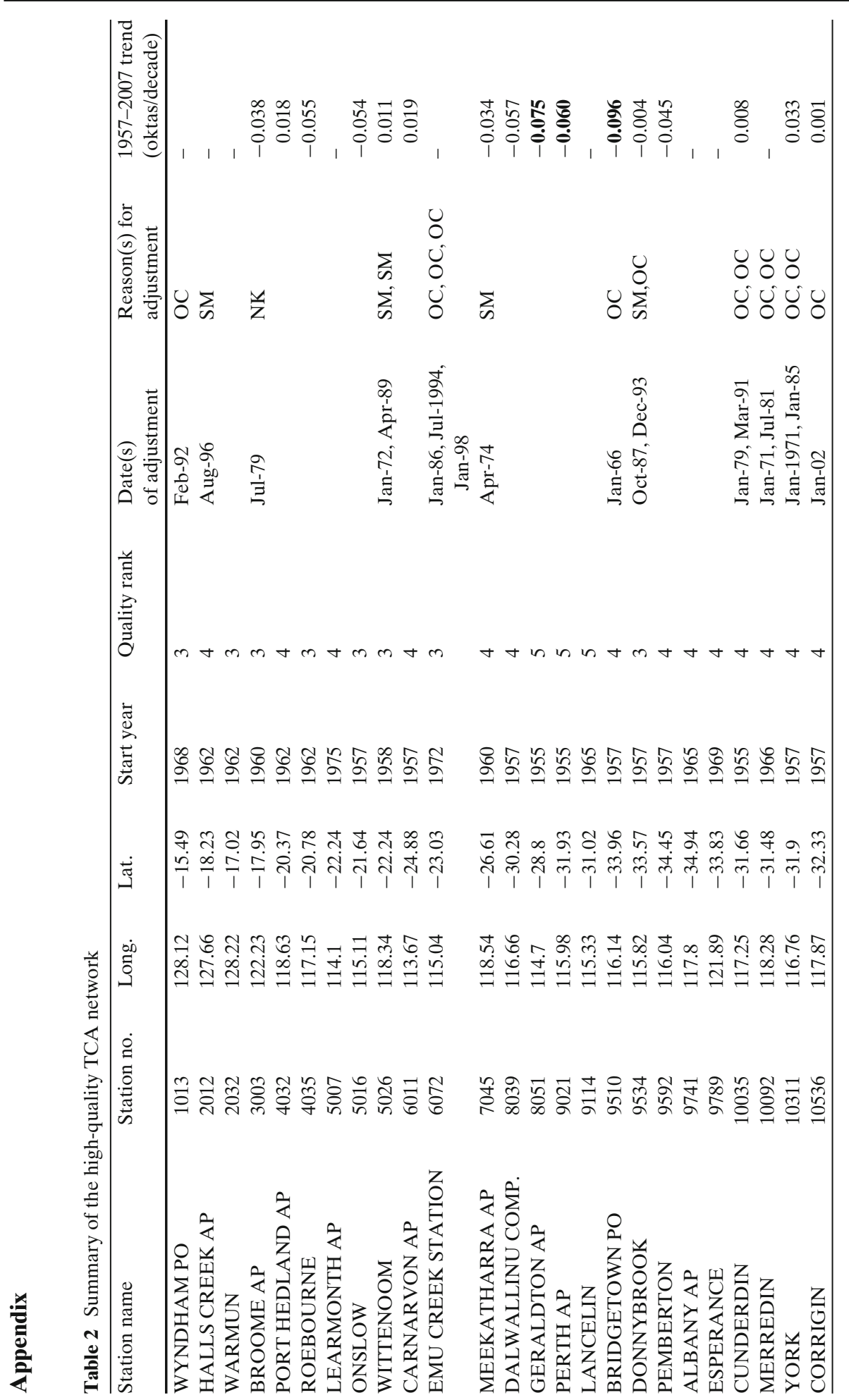




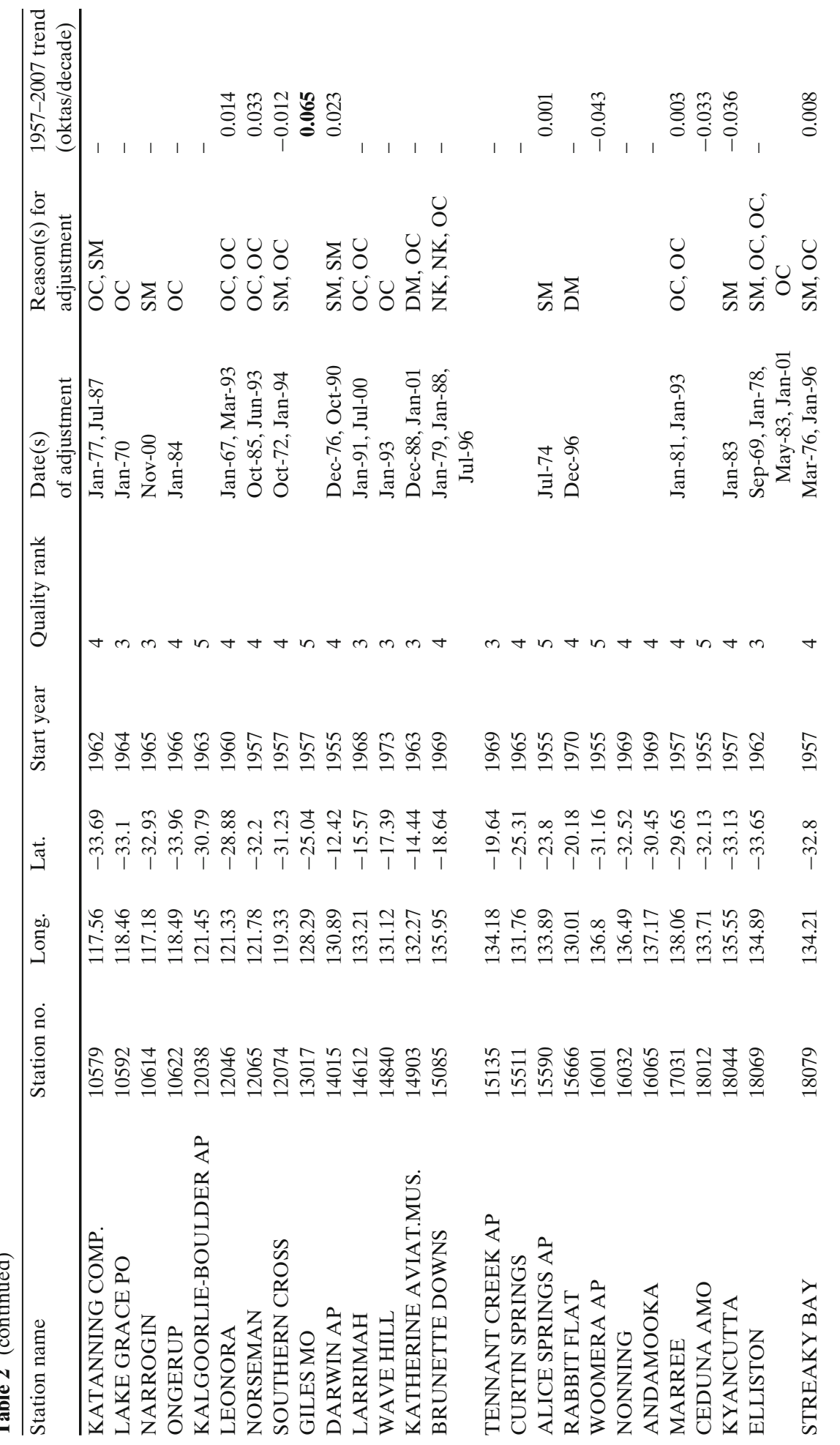




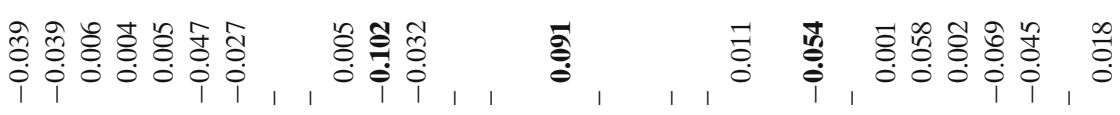

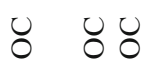

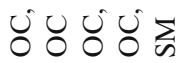

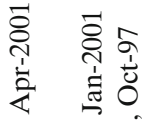

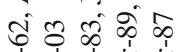

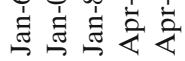

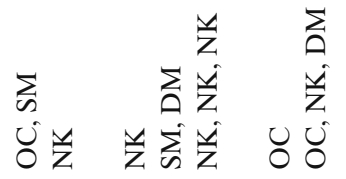<smiles>CCCCC</smiles>

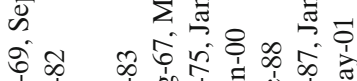

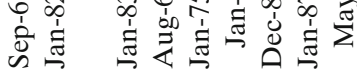

0
0
0
0
0

○

نं
啇

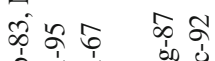

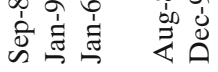

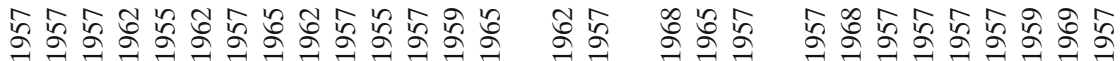

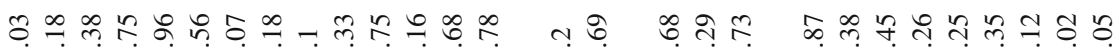

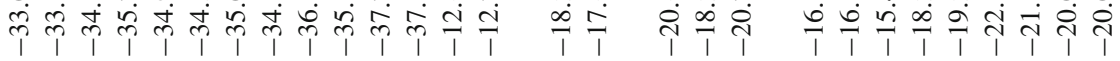

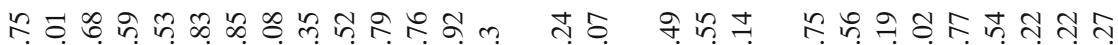

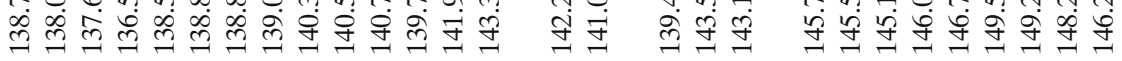

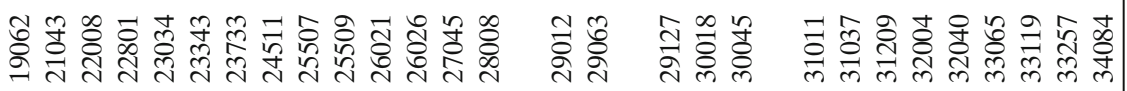

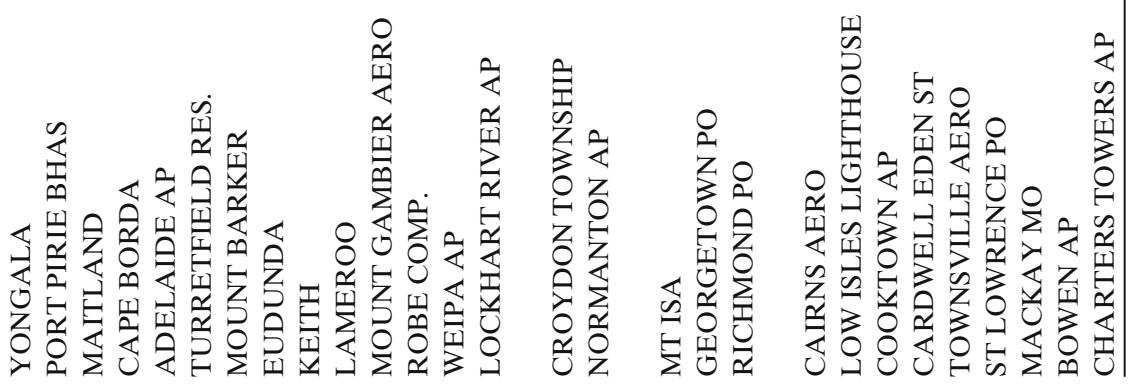




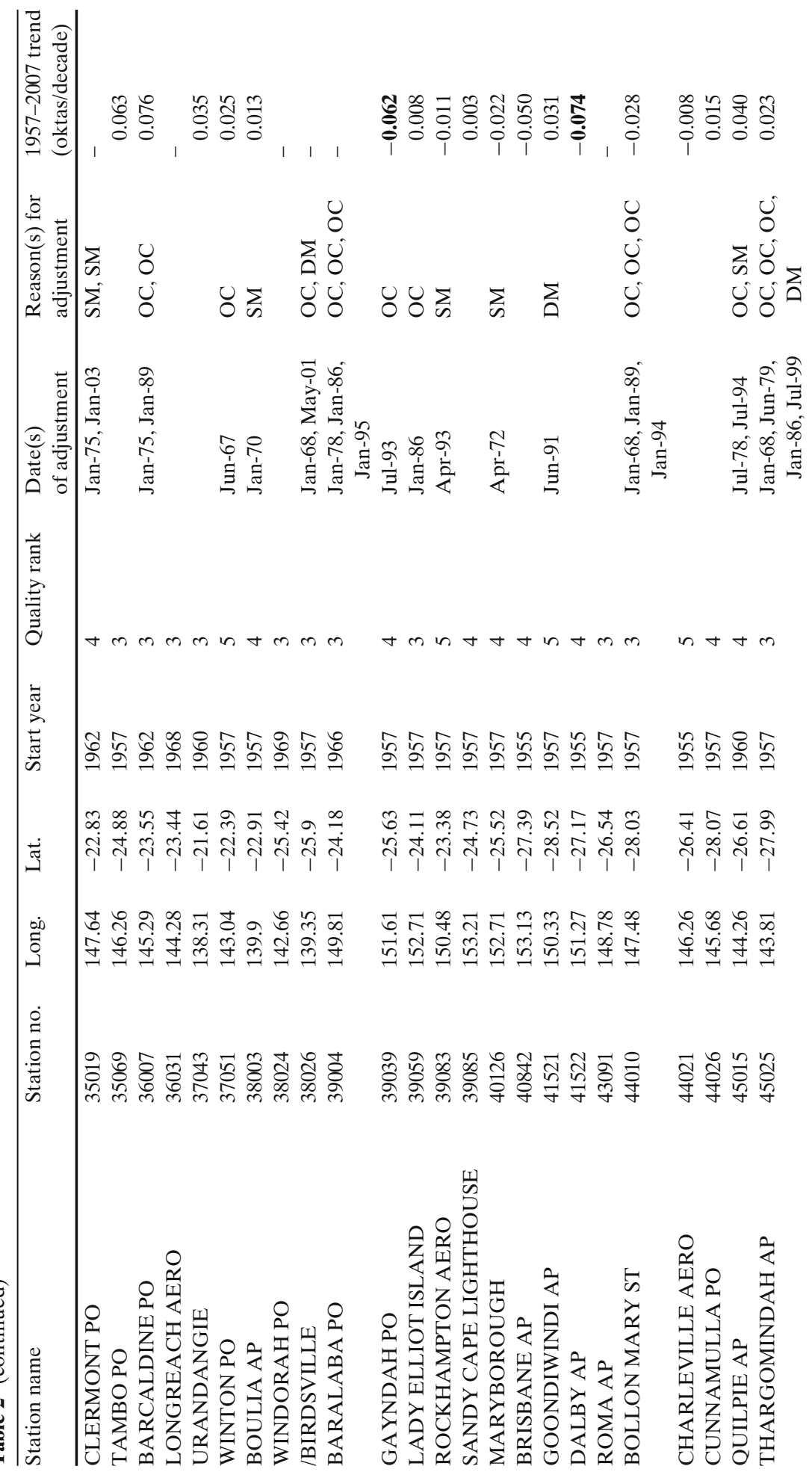




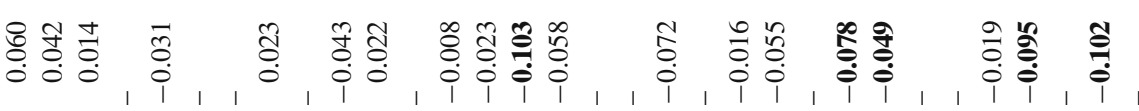

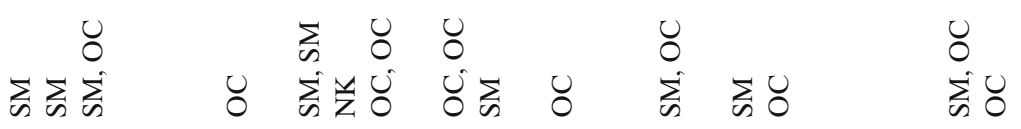

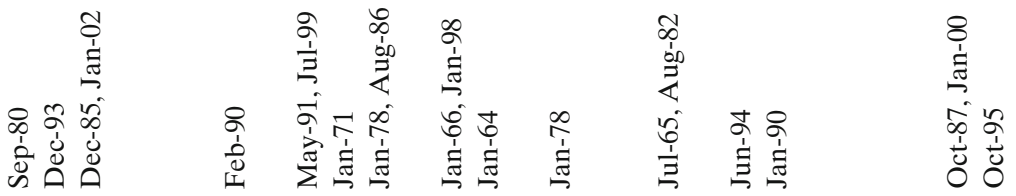

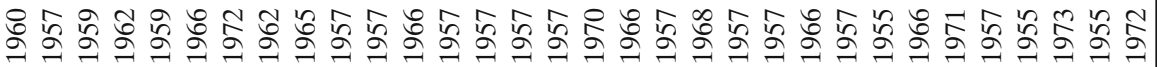

भ

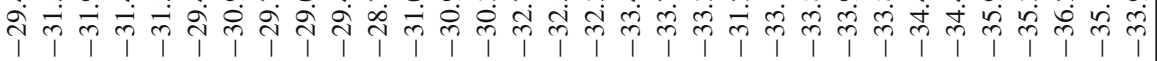

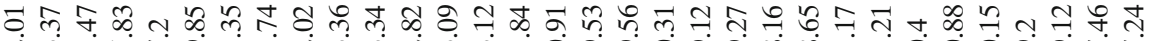
先守守守守至

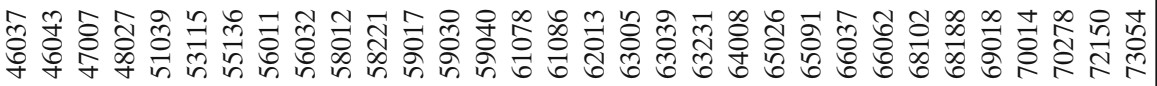

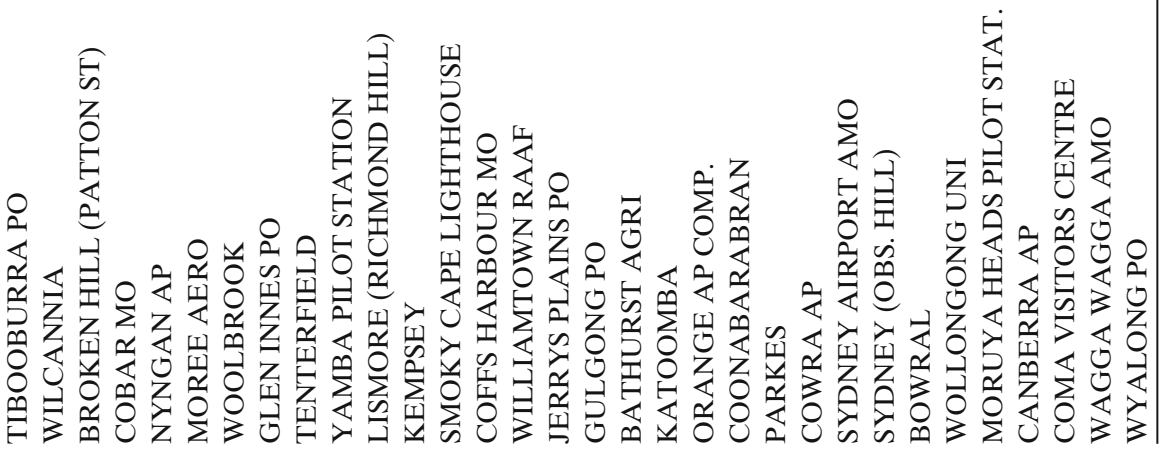




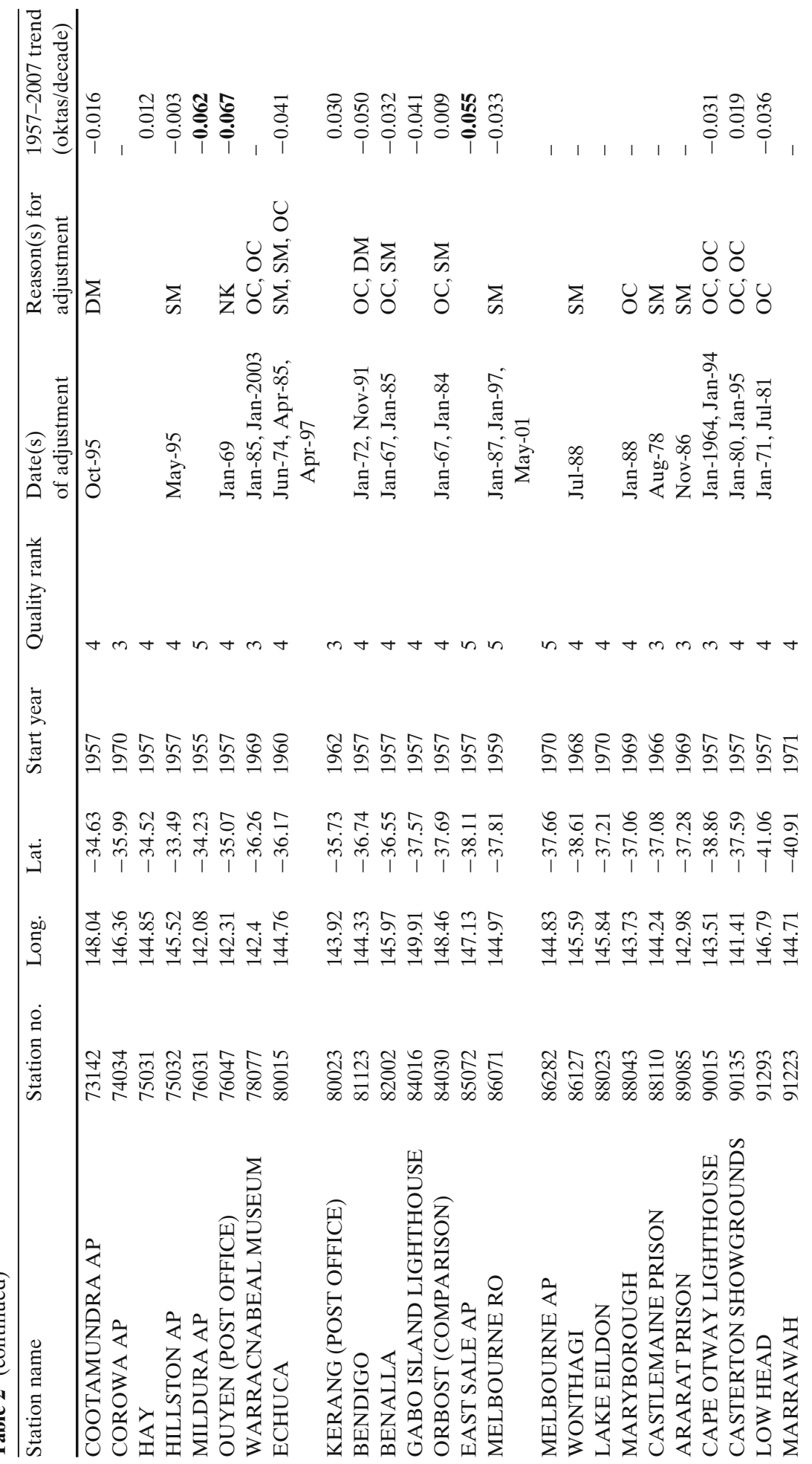




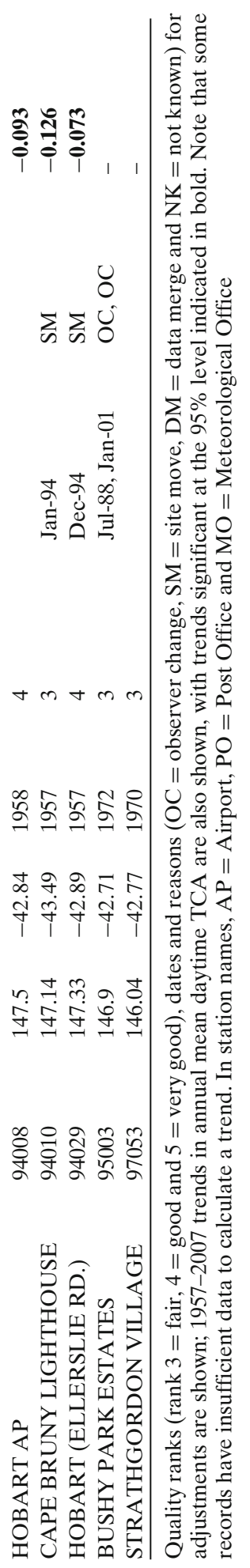




\section{References}

Auer I, Böhm R, Jurkovic A, Lipa W, Orlik A, Potzmann R, Schöner W, Ungersböck M, Matulla C, Briffa K, Jones P, Efthymiadis D, Brunetti M, Nanni T, Maugeri M, Mercalli L, Mestre O, Moisselin J-M, Begert M, Müller-Westermeier G, Kveton V, Bochnicek O, Stastny P, Lapin M, Szalai S, Szentimrey T, Cegnar T, Dolinar M, Gajic-Capka M, Zaninovic K, Majstorovic Z, Nieplova E (2007) HISTALP-historical instrumental climatological surface timeseries of the Greater Alpine Region. Int J Climatol 27:7-46

Barnes SL (1964) A technique for maximizing detail in numerical weather map analysis. J Appl Meteorol 3:396-409

Bony S, Colman R, Kattsov VM, Allan RP, Bretherton CS, Dufresne JL, Hall A, Hallegatte S, Holland MM, Ingram W, Randall DA, Soden BJ, Tselioudis G, Webb MJ (2006) How well do we understand and evaluate climate change feedback processes? J Climate 19:3445-3482

BoM (2000) Climatic Atlas of Australia-Rainfall. Available from Australian Bureau of Meteorology, Melbourne, Victoria, Australia, p 25

BoM (2001) Surface observation handbook, vol 2, Part 7, cloud observations. Bureau of Meteorology, Melbourne, p 2

BoM (2008) Special Climate Statement 16: Long-term rainfall deficiencies continue in southern Australia while wet conditions dominate the north. Available from Australian bureau of Meteorology, Melbourne, Victoria, Australia, p 9 http:/www.bom.gov.au/climate/current/index.shtml

Braganza K, Karoly DJ, Arblaster JM (2004) Diurnal temperature range as an index of global climate change during the twentieth century. Geophys Res Lett 31:L13217. doi:10.1029/2004GL019998

Clarkson NM (2002) CLIMARC: a project to extend the Australian computerised Climate Archives: final report to Land \& Water Australia. Bureau of Meteorology, Melbourne

Dai A, Trenberth KE, Karl TR (1999) Effects of clouds, soil moisture, precipitation, and water vapor on diurnal temperature range. J Climate 12:2451-2473

Dai A, Karl TR, Sun B, Trenberth KE (2006) Recent trends in cloudiness over the united states: a tale of monitoring inadequacies. Bull Am Meteorol Soc 87:597-606. doi:10.1175/BAMS-87-5-597

Della-Marta P, Collins D, Braganza K (2004) Updating Australia's high-quality temperature dataset. Aust Meteorol Mag 53(2):75-93

Evan AT, Heidinger AK, Vimont DJ (2007) Arguments against a physical long-term trend in global ISCCP cloud amounts. Geophys Res Lett 34:L04701, doi:10.1029/2006GL028083

Groisman PY, Knight RW, Karl TR, Easterling DR, Sun B, Lawrimore JH (2004) Contemporary changes of the hydrological cycle over the contiguous United States: trends derived from in situ observations. J Hydrometeorol 5:64-85

Henderson-Sellers A (1992) Continental cloudiness changes this century. Geo J 27:255-262

Jacobowitz H, Stowe LL, Ohring G, Heidinger A, Knapp K, Nalli NR (2003) The advanced very high resolution radiometer pathfinder atmosphere (PATMOS) climate dataset: a resource for climate research. Bull Am Meteorol Soc 84:785-793

Jakob D (2006) Detecting and attributing increase in rainfall in northwest Australia. 17th AustraliaNew Zealand climate forum, Australian National University, Canberra, ACT, Australia, p 24

Jakob C, Reeder M, Louey-Gung J (2009) Rainfall mechanisms over inland northwestern Australia and possible links to recently observed trends. 9th international conference on southern hemisphere meteorology and oceanography, Melbourne, Australia, p 86

Jones PA, Henderson-Sellers A (1992) Historical records of cloudiness and sunshine in Australia. J Climate 5:260-267

Jones DA, Trewin BC (2000) On the relationships between the El Niño-southern oscillation and Australian land surface temperature. Int J Climatol 20:697-719

Jovanovic B, Jones DA, Collins D (2008) A high-quality monthly pan evaporation dataset for Australia. Clim Change 87:517-535

Kaiser DP (1998) Analysis of total cloud amount over China, 1951-1994. Geophys Res Lett 25:3599_ 3602

Kaiser DP (2000) Decreasing cloudiness over China: an updated analysis examining additional variables. Geophys Res Lett 27:2193-2196

Koch SE, DesJardins M, Kochin PJ (1983) An interactive Barnes objective map analysis scheme for use with satellite and conventional data. J Clim Appl Meteorol 22:1487-1503

Kruger AC (2007) Trends in cloud cover from 1960-2005 over South Africa. Water SA 33:603-608 (Available online at www.wrc.org.za)

Lavery BM, Kariko A, Nicholls N (1992) A historical rainfall data set for Australia. Aust Meteorol Mag 40(1):33-39 
Lucas C (2006) A high-quality humidity dataset for Australia. 17th Australia New Zealand climate forum. Australian National University, Canberra, p 35

Maugeri M, Bagnati Z, Brunetti M, Nanni T (2001) Trends in Italian total cloud amount, 1951-1996. Geophys Res Lett 28:4551-4554

MilewskaVan Neil TG, Tao Li L, Roderick ML, Rayner DP, Ricciardulli L, Donohue RJ E (2004) Baseline cloudiness trends in Canada 1953-2002. Atmos-Ocean 42:267-280. doi:10.3137/ao.420404

McVicar TR, Van Neil TG, Tao Li L, Roderick ML, Rayner DP, Ricciardulli L, Donohue RJ (2008) Wind speed climatology and trends for Australia, 1975-2006: capturing the stilling phenomenon and comparison with near-surface reanalysis output. Geophys Res Lett 35:L20403. doi:10.1029/2008GL035627

Morton FI (1983) Operational estimate of areal evapotranspiration and their significance to the science and practice of hydrology. J Hydrol 66:1-6

Murray-Darling Basin Commission (2007) River Murray system-drought update No. 7. 8pp. Available from http://www.mdbc.gov.au/rmw/drought_updates

Palle E, Butler CJ (2002) Comparison of sunshine records and synoptic cloud observations: a case study for Ireland. Phys Chem Earth 27:405-414

Power S, Tseitkin F, Torok SJ, Lavery B, Dahni R, McAvaney B (1998) Australian temperature, Australian rainfall and the southern oscillation, 1910-1992: coherent variability and recent changes. Aust Meteorol Mag 47:85-101

Rayner DP (2007) Wind run changes: the dominant factor affecting pan evaporation trends in Australia. J Climate 20:3379-3394

Rossow WB, Schiffer RA (1999) Advances in understanding clouds from ISCCP. Bull Am Meteorol Soc 80:2261-2287

Seaman RS (1989) Tuning the Barnes objective analysis parameters by statistical interpolation theory. J Atmos Ocean Technol 6:993-1000

Smith I (2004) An assessment of recent trends in Australian rainfall. Aust Meteorol Mag 53:163-173

Solomon S, Qin D, Manning M, Chen Z, Marquis M, Averyt KB, Tignor M, Miller HL (eds) (2007) Climate change: the physical science basis. Contribution of working Group I to the fourth assessment report of the intergovernmental panel on climate change. Cambridge University Press, Cambridge (available from ipcc-wg1.ucar.edu)

Stone DA, Weaver AJ (2003) Factors contributing to diurnal temperature range trends in twentieth and twenty-first century simulations of the CCCma coupled model. Clim Dyn 20:435-445

Sun B, Groisman PY (2000) Cloudiness variations over the former Soviet Union. Int J Climatol 20:1097-1111

Sun B, Groisman PY, Mokhov II (2001) Recent changes in cloud-type frequency and inferred increases in convection over the United States and the Former USSR. J Clim 14:1864-1880

Timbal B, Arblaster JM, Power S (2006) Attribution of the late-twentieth-century rainfall decline in Southwest Australia. J Clim 19:2046-2062

Torok SJ, Nicholls N (1996) A historical annual temperature dataset for Australia. Aust Meteorol Mag 45(4):251-260

Trenberth KE (2002) Changes in tropical clouds and radiation: are they real? Science 296:2095. [Available online at www.sciencemag.org/cgi/content/full/296/5576/2095a.]

Trewin BC (2001) Extreme temperature events in Australia. Ph.D. thesis. University of Melbourne, Australia

Wang XL (2008) Penalized maximal F test for detecting undocumented mean shift without trend change. J Atmos Ocean Technol 25:368-384

Wang XL, Feng Y (2007) RHTestV2 user manual. Available from http://cccma.seos.uvic.ca/ ETCCDMI/RHtest/RHtestV2_UserManual.doc

Wang XL, Wen QH, Wu Y (2007) Penalized maximal t test for detecting undocumented mean change in climate data series. J Appl Meteorol Climatol 46:916-931. doi:10.1175/JAM2504.1

Warren SG, Eastman RM, Hahn CJ (2007) A survey of changes in cloud cover and cloud types over land from surface observations 1971-96. J Clim 20:717-738 